\title{
A Lei Federal 11.888 e a assistência técnica gratuita para o projeto de habitação do município de Teófilo Otoni-MG
}

\author{
Federal Law 11.888 and free technical assistance for the housing project in the municipality of \\ Teófilo Otoni-MG \\ Ley Federal 11.888 y asistencia técnica gratuita para el proyecto de vivienda en el municipio de \\ Teófilo Otoni-MG
}

Sérlio Souza de Almeida ORCID: https://orcid.org/0000-0002-5130-4552 Universidade Federal dos Vales do Jequitinhonha e Mucuri, Brasil E-mail: serlioadvogado@yahoo.com.br

Raquel de Souza Pompermayer ORCID: https://orcid.org/0000-0002-2455-3027 Universidade Federal dos Vales do Jequitinhonha e Mucuri, Brasil E-mail: raquel.pomper@ufvjm.edu.br

Marcio Coutinho de Souza ORCID: https://orcid.org/0000-0002-4238-1572 Universidade Federal dos Vales do Jequitinhonha e Mucuri, Brasil E-mail: marcio.souza@ufvjm.edu.br

Mauro Lúcio Franco

ORCID: https://orcid.org/0000-0003-2114-4399

Universidade Federal dos Vales do Jequitinhonha e Mucuri, Brasil

E-mail: ml.franco@ufvjm.edu.br

Ivana Carneiro Almeida

ORCID: https://orcid.org/0000-0001-6069-919X

Universidade Federal dos Vales do Jequitinhonha e Mucuri, Brasil

E-mail: ivana.carneiro@ufvjm.edu.br

Geórgia Fernandes Barros

ORCID: https://orcid.org/0000-0003-1362-9548

Universidade Federal dos Vales do Jequitinhonha e Mucuri, Brasil

E-mail: georgia.barros@ufvjm.edu.br

Wederson Marcos Alves

ORCID: https://orcid.org/0000-0002-1105-1300

Universidade Federal dos Vales do Jequitinhonha e Mucuri, Brasil

E-mail: wederson.alves@ufvjm.edu.br

Alexandre Sylvio Vieira da Costa

ORCID: https://orcid.org/0000-0001-7251-7816

Universidade Federal dos Vales do Jequitinhonha e Mucuri, Brasil

E-mail: alexandre.costa@ufvjm.edu.br

Agnaldo Keiti Higuchi

ORCID: https://orcid.org/0000-0001-8719-6154

Universidade Federal dos Vales do Jequitinhonha e Mucuri, Brasil

E-mail: agnaldo.higuchi@ufvjm.edu.br

Emiliane Aparecida Santos

ORCID: https://orcid.org/0000-0003-1385-7911

Universidade Federal dos Vales do Jequitinhonha e Mucuri, Brasil

E-mail: emiliane.santos@gmail.com

Samuel Pereira Rodrigues

ORCID: https://orcid.org/0000-0002-6090-1332

Universidade Federal dos Vales do Jequitinhonha e Mucuri, Brasil

E-mail: samupereira31@ hotmail.com

\section{Resumo}

De acordo com a Constituição Federal, a moradia é um direito fundamental do indivíduo e está ligada diretamente à garantia da dignidade humana. Este trabalho tem como objetivo analisar a aplicação da Lei Federal $n^{\circ} 11.888 / 08$, que trata da assistência técnica pública e gratuita para o projeto e a construção de habitação de interesse social, com relação aos potenciais benefícios para as famílias que recebem até três salários mínimos. A pesquisa foi realizada na cidade de Teófilo Otoni-MG, e partir dos dados obtidos em documentos impressos e arquivados no Centro de Referência de Assistência Social (CRAS-Sul), buscou-se realizar uma análise das condições das moradias, do perfil 
das famílias e das necessidades prioritárias para a confecção de projeto e o acompanhamento público gratuito, por técnicos de engenharia civil, urbanismo e arquitetura. Foram focalizados os bairros mais carentes da região sul da cidade, que se classificam como área de risco e violência. Foram levantados, por meio da pesquisa documental, dados sobre acessos à coleta de lixo, água e esgotamento sanitário canalizados, medição individual de energia, edificação de novos cômodos e dormitórios e acessibilidade. Com base nesses dados foram elencados os bairros e os tipos de ação prioritárias para cada bairro. Os resultados mostram que os bairros Jardim São Paulo, Taquara, Cidade Nova, Vila Barreiros e Vila Esperança apresentam os piores índices no tocante às variáveis analisadas, por isso devem ter prioridade para receber os benefícios da Lei Federal $n^{\circ} 11.888 / 08$. Como implicação gerencial em administração pública, sugere-se o envolvimento de novos atores, com a elaboração de convênios e parcerias entre o Executivo Municipal e organizações que possam facilitar a assistência técnica pública e gratuita, no projeto e execução de obras que beneficiem as moradias identificadas.

Palavras-chave: Lei Federal $n^{\circ}$ 11.888/08; Assistência técnica pública gratuita; Zona sul do município de Teófilo Otoni; Diagnóstico moradias; Residências assistidas pelo CRAS-Sul.

\begin{abstract}
According to the Brazil Federal Constitution, housing is a fundamental right of the individual and is directly linked to the guarantee of human dignity. This paper aims to analyze the application of Federal Law 11888/08, which deals with public and free technical assistance for the design and construction of social housing, with regard to the potential benefits for families receiving up to three minimum wages. The research was carried out in the city of Teófilo OtoniMG, and from the data obtained in printed documents made available by the Social Assistance Reference Center (CRAS-Sul), an analysis of the conditions of the houses, the profile of the families and the priority needs for the design of the project and free public support by technicians of civil engineering, urbanism and architecture were made. The poorest neighborhoods in the southern region of the city, classified as areas of risk and violence were the locus of the study. Data of garbage collection, channeled water and sewage, individual energy measurements, building of new rooms and bedrooms and accessibility were collected through documentary research. Based on this data, the neighborhoods and priority types of action for each neighborhood were listed. The results show that the neighborhoods Jardim São Paulo, Taquara, Cidade Nova, Vila Barreiros and Vila Esperança have the worst rates in terms of the variables analyzed, so they must have priority to receive the benefits of Federal Law No. 11,888 / 08. As a managerial implication in public administration, the involvement of new actors is suggested, with the elaboration of covenants and partnerships between the Municipal Executive and organizations that can facilitate public and free technical assistance, in the design and execution of works that benefit the identified homes.
\end{abstract}

Keywords: Federal Law No. 11.888 / 08; Free public technical assistance; South zone of the Municipality of Teófilo Otoni; Houses at risk.

\title{
Resumen
}

Según la Constitución Federal de Brasil, la vivienda es un derecho fundamental del individuo y está directamente vinculado a la garantía de la dignidad humana. Este trabajo tiene como objetivo analizar la aplicación de la Ley Federal 11888/08, que trata de la asistencia técnica pública y gratuita para el diseño y construcción de viviendas sociales, en cuanto a los potenciales beneficios para las familias que perciben hasta tres salarios mínimos. La investigación se realizó en la ciudad de Teófilo Otoni-MG, y a partir de los datos obtenidos en documentos impresos puestos a disposición por el Centro de Referencia de Asistencia Social (CRAS-Sul), se realizó un análisis de las condiciones de las viviendas, el perfil de las famílias, y se hicieron las necesidades prioritarias para el diseño del proyecto y el apoyo público gratuito por parte de técnicos de ingeniería civil, urbanismo y arquitectura. Los barrios más pobres de la región sur de la ciudad, clasificados como áreas de riesgo y violencia, fueron el lugar del estudio. Se recolectaron datos de recolección de basura, agua canalizada y alcantarillado, mediciones de energía individual, construcción de nuevas habitaciones y dormitorios y accesibilidad a través de una investigación documental. Con base en estos datos, se enumeraron los barrios y los tipos de acción prioritarios para cada barrio. Los resultados muestran que los barrios Jardim São Paulo, Taquara, Cidade Nova, Vila Barreiros y Vila Esperança tienen las peores tasas en términos de las variables analizadas, por lo que deben tener prioridad para recibir los beneficios de la Ley Federal $\mathrm{N}^{\circ}$ 11.888 / 08. Como implicación gerencial en la administración pública, se sugiere la participación de nuevos actores, con la elaboración de convenios y alianzas entre el Ejecutivo Municipal y organismos que puedan facilitar la asistencia técnica pública y gratuita, en el diseño y ejecución de obras que beneficien a los hogares identificados.

Palabras clave: Ley Federal $\mathrm{n}^{\circ} 11.888$ / 08; Asistencia técnica pública gratuita; Zona Sur del municipio Teófilo Otoni; Diagnóstico vivienda; Residencias asistidas por CRAS-Sur.

\section{Introdução}

Segundo Watt (2018) o 'direito à cidade' foi originado com Henri Lefebvre no fim dos anos de 1960. Ao considerar o

habitat urbano, o autor enfoca a importância do pensar em habitação, principalmente, para os menos favorecidos. Assim, 
considera-se que as famílias de baixa renda necessitam de moradias que estejam adequadas às posturas legislativas municipais, proporcionando conforto ambiental, higiene, segurança e acessibilidade (Mitidiero, 2007).

A habitação adequada é um direito fundamental de todo ser humano e sua família, prevista na Declaração Universal dos Direitos Humanos de 10 de dezembro de 1948 e no Pacto Internacional dos Direitos Econômicos, Sociais e Culturais de 16 de dezembro de 1966, adotados e proclamados pela Organização das Nações Unida (ONU/BR, 2016 apud Vieira \& Basto, 2020, p. 4).

No Brasil, a Constituição Federal de 1988 inseriu em seu art. $6^{\circ}$ os direitos sociais do cidadão, "a educação, a saúde, a alimentação, o trabalho, a moradia, o transporte, o lazer, a segurança, a previdência social, a proteção à maternidade e à infância, a assistência aos desamparados, na forma desta Constituição" (Brasil, 1988, p. 18). Inserida na Carta Magna, a moradia como direito fundamental do indivíduo amplia a perspectiva da dignidade humana, a ser averiguada pelo Estado por mecanismos capazes de dar cumprimento a esse direito, com o viés de soberania constitucional (Moraes, 2017).

Para que este direito fundamental inserido na Constituição Federal possa ser colocado em prática, é necessário que haja uma legislação regulamentadora que pormenorize o tempo e o modo de sua aplicação. Desta forma, dez anos após a promulgação da Lei Máxima, foi editada, em 24 de dezembro de 2008, a Lei Federal de $\mathrm{N}^{\circ} 11.888$, que regulou nas esferas do Poder Público, municipal, estadual e federal, o acesso à assistência técnica pública gratuita para o projeto, reforma, ampliação, construção e a regularização de moradia às famílias de renda não superior a três salários mínimos, que residam em áreas urbanas ou rurais (Brasil, 2008). Essas famílias têm o direito à assistência técnica pública gratuita necessária ao alcance da execução pretendida, fornecida pelos profissionais das áreas de arquitetura, urbanismo e engenharia civil (Moraes, 2017).

Apesar do direito à moradia estar inserida na Constituição Federal e devidamente pormenorizado por Legislação Federal, percebe-se a persistente ausência de política habitacional e estrutura das três esferas dos entes federados para aplicação da assistência técnica pública e gratuita nos termos da Lei Federal 11.888/08 (Brasil, 2008). Além das lacunas da política nacional de habitação, especialmente as que caracterizam as moradias de famílias com renda inferior a três salários mínimos, destaca-se a ausência da oferta gratuita de profissionais técnicos na confecção do projeto e acompanhamento da edificação habitacional. Acrescenta-se, ainda, a necessidade de estruturação e capacitação dos municípios para receberem verba federal vinculada a este fim.

Por esta percepção, o presente trabalho tem como objetivo analisar a aplicação da Lei Federal no 11.888/08, que trata da assistência técnica pública e gratuita para o projeto e a construção de habitação de interesse social, com relação aos potenciais benefícios para as famílias que recebem até três salários mínimos.

A pesquisa foi realizada na cidade de Teófilo Otoni-MG, e partir dos dados obtidos em documentos impressos e arquivados no Centro de Referência de Assistência Social (CRAS-Sul), buscou-se realizar uma análise das condições das moradias, do perfil das famílias e das necessidades prioritárias para a confecção de projeto e o acompanhamento público gratuito, por técnicos de engenharia civil, urbanismo e arquitetura. Foram focalizados os bairros mais carentes da região sul da cidade, que se classificam como área de risco e violência.

Foram considerados os bairros Cidade Nova, Frei Júlio, Jardim São Paulo, São Benedito, Taquara, Vila Barreiros, Vila Esperança (que engloba Vilinha), Vila Jacaré e Vila Progresso (que engloba Tancredo Neves) do Município de Teófilo Otoni-MG, esse diagnóstico considerou o período de 2012 a 2017 (PMTO, 2017).

Diante desse quadro, é proposto o seguinte questionamento como problema de pesquisa: Quais fatores são responsáveis pela ausência de acompanhamento técnico e gratuito para o projeto e a construção de habitação de interesse social, para as famílias que recebem até três salários mínimos nos bairros carentes da região sul de Teófilo 


\section{Otoni-MG?}

$\mathrm{O}$ artigo foi organizado em 5 partes, além da introdução e das referências. O aparato teórico aborda a crescente demanda por uma política habitacional mais inclusiva e a dificuldade de os governos municipais de atenderem, devido às limitações de dotação orçamentaria e técnica. Posteriormente, é analisada a Lei $\mathrm{n}^{\circ}$ 11.888/08 como mecanismo federal instituído no intuito de garantir à população de baixa renda o acesso à assistência técnica gratuita. No item 4 é apresentada a metodologia utilizada para a realização dessa pesquisa e no item 5 apontados e analisados os resultados encontrados para os bairros carentes da região sul de Teófilo Otoni.

\section{A População Atendida pela Política Habitacional de Interesse Social}

O crescimento populacional do Brasil foi vertiginoso após a década de 1950. Entre os anos de 1950 e 1980, houve um acréscimo próximo de setenta milhões de habitantes. Com a expansão populacional sem políticas públicas definidas, tampouco recursos financeiros para aquisições de moradias dignas, se amplia o número de cortiços e residências autoconstruídas sem quaisquer orientações técnicas, constituindo favelas periféricas (Reis \& Lay, 2010).

Os governos, por décadas, priorizaram a formação de empreendimentos em larga escala, na tentativa de acompanhar o crescimento populacional. Entretanto, a maior parcela da população apresenta renda total familiar com valores inferiores a três salários mínimos. Com esta faixa salarial, a renda familiar é exígua, o que dificulta o comprometimento com as parcelas mensais ofertadas. A inadimplência inviabilizava a edificação de novos empreendimentos quebrando a cadeia produtiva (Freitas, 2004).

Com este entrave, no ano de 2007 inicia-se um intenso debate em diversos setores representativos da comunidade, objetivando alcançar uma política do setor que considerasse a realidade brasileira, como déficit habitacional, diversidade territorial, culturas regionais distintas, renda per capita, limitações administrativas estaduais e municipais, bem como a crescente demanda. Mas os planejamentos sempre se esbarravam no limitador orçamentário e recursos subsidiados. Pois ainda que fossem formados novos conjuntos, não solucionariam os problemas dos aglomerados habitacionais existentes (Bonduki, 2008).

$\mathrm{Na}$ tentativa de o governo atender a esta faixa de baixa renda, promoveram-se financiamentos para aquisição de material de construção para o proprietário de um lote, que desejasse edificar sua moradia ou aquele que necessitasse de melhoria em sua habitação pré-existente. A verba liberada, não incluía o técnico para a elaboração do projeto, tampouco o acompanhamento das obras, o que acarretava uma autoconstrução e autogestão, que pela ausência de conhecimento contribuiu para o desperdício de material, construção de edificações desregulamentadas, ausência de adequação ambiental e lógica de edificação, obras inacabadas, aumento dos índices de acidentes domésticos e a aparência de favelamento (Rolnik, Cymbalista \& Nakano, 2008).

A família com renda de até três salários mínimos ficaram limitadas às prestações da aquisição do material de construção, não restando margem para contratação de técnico capacitado a orientar, desde o projeto até o término da construção. Os governos municipais não possuíam dotação orçamentária específica para conceder essa mão de obra à população carente.

Desta forma, o Legislativo Federal, através da Lei 11.888/08, na tentativa de sanar esta deficiência, apontou sob o prisma de orçamento federal (FNHIS) vinculado à moradia (mas que na prática não alcançava o objetivo fim, que é a população), a possibilidade desta camada menos favorecida de ter o acesso, sem quaisquer custos à assistência técnica pública gratuita de engenheiros e arquitetos desde o projeto até a finalização da sua obra. A lei prioriza as edificações realizadas em sistema de mutirão, com o intuito de minimizar os custos totais através da ausência de custo da mão-de-obra (Santos, 2012).

A inexistência do conhecimento da legislação e a indiferença dos governos nas três esferas distanciam a população 
destino final, de terem acesso a esta assistência técnica gratuita, que apesar de ter sido aprovada em 2008, até a presente data, pouco é difundida e menos ainda a sua aplicação prática (Nádia, 2016).

\section{A Lei Federal de $\mathbf{n}^{0} \mathbf{1 1 . 8 8 8 / 0 8}$}

A Lei Federal 11888-08 também conhecida como Lei da Assistência Técnica em Engenharia, foi sancionada em dezembro de 2008 e garante direito às famílias que tem renda de até três salários mínimos à assistência técnica pública e gratuita para edificação, reforma, ampliação ou regularização fundiária de habitações em área urbanas ou rurais. Se trata de um instrumento importante para agregar qualidade de vida à população de baixa renda e que, na maioria das vezes reside em locais distantes da escola e do trabalho. É necessário ocupar os vazios existentes nas cidades com moradias dignas e que tenham qualidade técnica.

A lei busca entre outros objetivos, viabilizar o desenvolvimento e organização habitacional urbana, através da assistência técnica gratuita, ofertada pelo Poder Público, desde o projeto, até o término da pretendida obra da residência da família que se enquadra como baixa renda. O que seria inacessível à massa populacional, que com a institucionalização do conceito propriedade, embasada no capital, foi forçada alojar-se à margem dos núcleos habitacionais, que tem características da ausência de amparo e infraestrutura das necessidades básicas de uma habitação condigna (Fernandes \& Alfonsin, 2014).

Para tanto, foram definidas as obrigações do poder público nas três esferas: municipal, estadual e federal. Para o atendimento do disposto na lei as ações devem ser planejadas e implementadas de forma coordenada e sistêmica, a fim de evitar sobreposições e otimizar resultados.

Com a descentralização do apoio técnico, o governo federal, fica na obrigatoriedade de distribuir verbas satisfatórias e proporcionais aos municípios que estejam aptos a conceder a assistência técnica gratuita nas áreas de arquitetura, urbanismo e engenharia, como o Fundo Nacional de Habitação de Interesse Social (FNHIS), bem como a fomentação de outros recursos oriundos do orçamento ou parcerias público privadas. Sem este suporte financeiro, praticamente é impossível que os municípios pratiquem a regulamentação e execução desta assistência técnica gratuita. Os orçamentos municipais em muito já se encontram esgotados e não estão conseguindo suprir os demais direitos sociais, como saúde e educação (Mitidiero, 2007).

Segundo Moraes (2012), a consolidação da intenção do Poder Público, através da atuação de suas três esferas, parcerias público privada e entidades acadêmicas, em atender, aprimorar, corrigir, planejar, otimizar, aproveitar, democratizar conhecimento, aperfeiçoamento qualitativo dos projetos, a inovação tecnológica, a atuação de engenharia, arquitetura e urbanismo nos módulos habitacionais executados pela população de baixa renda, evita a aglomeração de favelas em torno dos núcleos populacionais, que tem por consequência a insatisfação gerada pela afronta à dignidade humana.

Apesar da expressa determinação legal da Constituição Federal, constituindo ao cidadão o direito à moradia como preceito fundamental, pela ausência de interesse político, esta legislação se faz ineficaz. Poucos foram os municípios que promoveram a regulamentação e adequação, uma por ausência de recursos, outra por ausência de conhecimento e por fim o próprio envolvimento do agente público com a realização e incremento da dignidade dos seus comandados (Santos, 2016).

Cabem, pelo menos, duas perguntas em um país onde a figura do cidadão é tão esquecida. Quantos habitantes, no Brasil, são cidadãos? Quantos nem sequer sabem que não o são? O simples nascer investe o indivíduo de uma soma inalienável de direitos, apenas pelo fato de ingressar na sociedade humana. Viver, tornar-se um ser no mundo, é assumir, com os demais, uma herança moral, que faz de cada qual um portador de prerrogativas sociais. Direito a um teto, à comida, à educação, à saúde, à proteção contra o frio, a chuva, as intempéries; direito ao trabalho, à justiça, à liberdade e a uma existência digna (Santos, 2011, p. 58, apud Prado \& Santos, 2020, p. 7). 
Assim "o direito à moradia compreende mais do que o ato de ocupar um lugar no espaço, já que é preciso ter em conta a adequação do local em que se vive para o desenvolvimento psicossocial do sujeito" (Martins \& Mastrodi, 2018, p. 79). Mas como consequência da indiferença, estão os elevados custos à política pública em corrigir as catástrofes que ocorrem a cada evento climático ou até sismográfico, abarrotando as secretarias de Defesa Civil, que poderiam ser evitados com o trabalho preventivo e preditivo, reduzindo expressivamente o custo, sem contar a preservação de vidas e a elevação da autoestima da população de baixa renda, que se sentem valorizados quando possuem moradias condignas e respeitadas pelo poder público (Santos, 2016).

Um dos maiores entraves encontra-se no conhecimento do acesso a estas verbas. A Lei Federal 11.888/08 alterou a regulamentação com o Sistema Nacional de Habitação de Interesse Social (SNHIS), incluindo a assistência técnica gratuita ofertada pelas áreas de arquitetura e urbanismo (Brasil, 2008). A verba é disponibilizada aos municípios, porém, estes necessitam estar devidamente adequados, regulamentados e terem determinado as diretrizes através dos Planos Locais de Habitação de Interesse Social, em consonância com os Planos Diretores e os Planos de Proteção Ambiental (Moraes, 2012).

Dessa forma, existe uma necessidade de fomentar políticas públicas que considerem o fornecimento da assistência técnica gratuita para a construção de moradias das pessoas de baixa renda. Ao mesmo tempo, os municípios precisam gerenciar os recursos públicos destinados a esse fim, de modo a promover o aperfeiçoamento técnico, a melhoria habitacional, a estética visual dos núcleos habitacionais, tendo em vista a satisfação da dignidade humana. Ademais, o direito à moradia, não pode ser privilégio da elite que perfazem a minoria populacional.

\subsection{O acesso à assistência técnica gratuita}

Para melhor compreensão, a Figura 1 mostra uma síntese do trâmite a ser percorrido pelas famílias carentes, necessário para obter o acesso à verba federal disponível para o pagamento dos honorários dos profissionais que realizarão o projeto e acompanhamento da obra nas moradias de famílias com renda de até 03 salários mínimos, observado os termos da Lei Federal no 11.888/08, o Manual do Conselho Regional de Engenharia e Agronomia (CREA) e o Instituto de Arquitetos do Brasil (IAB) (Moraes, 2017). As Etapas para o acesso à assistência técnica gratuita:

$\mathbf{1}^{\text {a }}$ Etapa: para que sejam selecionadas as famílias que preencham os requisitos e para o planejamento das prioridades e acompanhamento das etapas de execução, o município, por meio de representações associativas da população ou órgãos governamentais próprios como o Centro de Referência de Assistência Social (CRAS) e setor de fiscalização e obras, promove o levantamento das necessidades e realizam a triagem nos termos da Lei Federal 11.888/08, como a situação física para regularização fundiária, área total territorial, infraestrutura disponível, preexistência e condicionantes, renda familiar, dentre outros.

O setor responsável do executivo municipal propõe ao Ministério das Cidades a convenção de convênio ou parceria para o repasse das verbas federais destinadas a assistência técnica gratuita. Estabelecido o convênio ou parceria, o Ministério das Cidades, através do agente financeiro (atualmente a Caixa Econômica Federal), disponibiliza os recursos financeiros às famílias a serem atendidas.

$2^{\mathbf{a}}$ Etapa: os atores habilitados profissionalmente, através de Lei aprovada pela Câmara Municipal, efetivam convênio ou parceria com o executivo municipal, para a seleção, qualificação e oferta de profissionais, gestão, acompanhamento das execuções e recebimento dos recursos para a assistência técnica.

Segundo a determinação da lista selecionada por prioridade, a família, contata um dos atores habilitados e apresenta sua necessidade técnica e financeira. O protagonista habilitado e a família pactuarão contrato contendo objeto, prazos, condições, remuneração, acompanhamento e fiscalização, para promover a devida assistência técnica necessária, como projeto e acompanhamento da construção, reforma ou melhoria, devidamente aprovado pelos órgãos públicos competentes, órgão 
fiscalizador - Conselho Regional de Engenharia e Agronomia (CREA) ou Instituto de Arquitetos do Brasil (IAB) e pleitear os recursos financeiros do governo federal, através da instituição financeira, para custear os serviços desta assistência.

Figura 1 - Macroestrutura do Programa de Assistência Técnica.

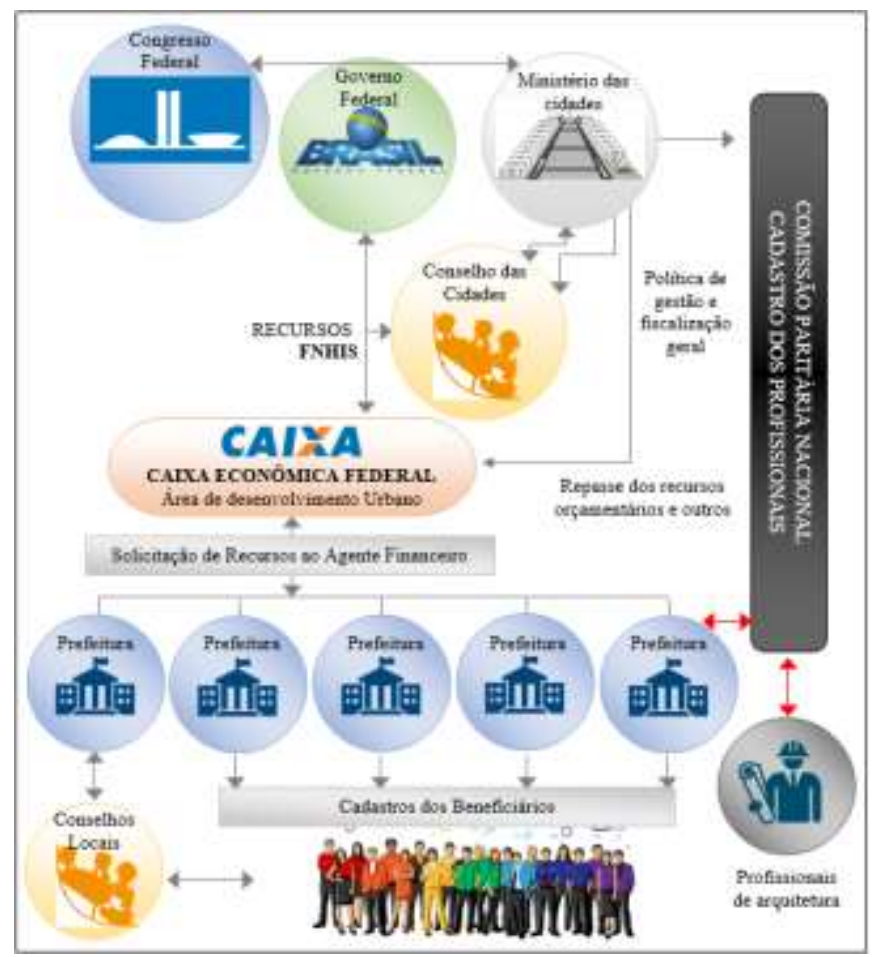

Fonte: Desenvolvido pelos autores a partir de Santos (2006)

$3^{\text {a }}$ Etapa: o técnico tem a responsabilidade pelo cumprimento das etapas e serviços definidos em contrato. Findo cada etapa é repassado a verba honorária pela instituição financeira.

$4^{\text {a }}$ Etapa: finalizado os serviços, é realizado um relatório de avaliação sobre a qualidade e conclusão, em conjunto pelo órgão fiscalizador do executivo municipal, técnicos, instituição financeira e a família, para a liberação da última parcela dos honorários.

Portanto, a assistência realizada com essas etapas é UNIVERSAL permite o acesso de todas as famílias com renda de até três salários mínimos e evita que se criem novas demandas de serviços, tendo em vista que o melhoramento da habitação, qualificando a moradia e reforçando as relações sociais existentes, exceto se as famílias estão localizadas em áreas de risco.

\section{Métodos e Técnicas Aplicados na Pesquisa}

Quanto à natureza, essa é uma pesquisa aplicada, que tem por fim, a geração de diagnóstico dos dados estatísticos (Gil, 2002) das moradias de famílias com renda inferior a três salários mínimos, situadas na Região Sul do Município de Teófilo Otoni-MG, assistida pelo CRAS-Sul.

Dessa forma, no intuito de se estabelecer um diagnóstico que possa subsidiar as decisões para a aplicação dos recursos financeiros federais vinculados à aplicação da Lei Federal 11.888/08. O objeto de estudo é a Cidade de Teófilo Otoni, situada no Estado de Minas Gerais. Particularmente, a pesquisa abrange a região sul da cidade, com os seguintes bairros destacados com a utilização de nomenclaturas: Cidade Nova, Conjunto Paulo Freire, Frei Júlio, Jardim São Paulo, São Benedito, Solidariedade, Tancredo Neves, Taquara, Vila Barreiros, Vila Esperança, Vila Jacaré, Vila Progresso e Vilinha.

Desse modo, realizou-se uma classificação dos bairros prioritários por assistência técnica pública e gratuita às 
moradias de família com renda de até três salários mínimos, bem como das ações prioritárias em cada bairro analisado. Para tanto, recorreu-se a uma pesquisa documental (Rolnik \& Nakano, 2008) com o propósito de evidenciar categorias e prioridades de ações vinculadas à aplicação da Lei Federal 11.888/08. A utilização da técnica de análise documental de um banco de dados secundários possibilitou a observação do perfil dos participantes, organização dos dados, interpretação e apresentação dos resultados de uma pesquisa de caráter qualitativo e quantitativo. Os dados são obtidos de um questionário aplicados pelo CRAS-Sul, no período 2012 a 2017, e disponibilizados pela Prefeitura Municipal de Teófilo Otoni.

Definiram-se variáveis que descrevem o perfil das famílias participantes e de suas moradias nos bairros selecionados. As variáveis estão dispostas por família e por moradia, sendo tabuladas e cruzadas pelo método estatística descritiva e tabela de referência cruzada, no programa estatístico GNU PSPP version 1.4.1-g79ad47. A estatística descritiva é constituída pelo conjunto de métodos destinados à organização e descrição dos dados através de indicadores sintéticos ou sumários (Silvestre, 2007).

Com o levantamento de prioridades de ação nos termos da Lei Federal 11.888/08, apontaram-se as necessidades das moradias das famílias com renda de até três salários mínimos. Os diagnósticos podem ser utilizados nas tomadas de decisão do público competente, quanto à formação de convênio entre os profissionais de arquitetura e engenharia civil com o executivo municipal da Cidade de Teófilo Otoni, como também no âmbito estadual e federal.

\subsection{Etapa de coleta dos dados no CRAS-Sul}

Esta etapa constitui de um levantamento de dados e definição de variáveis para a elaboração de um diagnóstico do perfil sócio econômico dos domicílios na área de abrangência do estudo. Para coletar os dados necessários a este estudo, o primeiro órgão visitado foi a Câmara Municipal de Teófilo Otoni, por se tratar de órgão municipal fundamental e diretamente interessado no objeto de estudo do presente trabalho.

O primeiro questionamento foi a respeito da possibilidade de acesso aos dados sociais das famílias de baixa renda no município de Teófilo Otoni, atendidas pelo Centro Regional de Assistência Social (CRAS), primeiramente localizadas na região mais carente do Município, o sul da cidade, para verificar as demandas existentes por assistência técnica para o projeto e a construção de moradias para às famílias de baixa renda. Logo, em entrevista com o presidente da Câmara Municipal, obtevese a confirmação de que as informações estariam disponíveis para o levantamento de dados necessários, através de acesso as fichas de diagnóstico social elaboradas pelo CRAS-Sul, contendo os dados sociais das famílias e moradias, cadastradas na referida regional.

A seleção da região sul do município deveu-se por ser a região mais carente do município e o fato de localizar-se nas proximidades do Campus Mucuri da Universidade Federal dos Vales do Jequitinhonha e Mucuri, que forma periodicamente profissionais habilitados em Engenharia Civil.

Os Centros de Referência da Assistência Social (CRAS) são órgãos que integram o Conselho Municipal de Assistência Social (CMAS) que pertence a Secretaria Municipal de Assistência Social de Teófilo Otoni que integram a política do Sistema Único de Assistência Social (SUAS). Os CRAS estão divididos entre as regionais do Município de Teófilo Otoni sendo: Sudeste, Nordeste, Oeste e Sul.

Sendo assim, a pesquisa passou para uma nova etapa que consistiu na triagem de dados junto ao CRAS-Sul, mediante a disponibilização das fichas de diagnóstico social das famílias atendidas pela regional. Utilizando-se dos questionários levantados pelos Agentes do CRAS-Sul, foram identificadas algumas variáveis, tais como: ano de cadastro no CRAS-Sul, tipo de residência, material das paredes externas, acesso à energia elétrica, água canalizada, forma de abastecimento de água, esgotamento sanitário, coleta de lixo, número total de cômodos, número de cômodos utilizados como dormitórios, número de pessoas da residência dividido pelo número de dormitórios, número de residências com acesso para deficientes de locomoção, 
número de residência situada em área de risco, área de risco de desabamento ou alagamento, localizada em área de difícil acesso geográfico, localizada em área com forte presença de conflito/violência, faixa etária, renda per capita e tempo de moradia no bairro. Algumas dessas variáveis foram tratadas nessa pesquisa.

Estes dados permitiram compreender o grau de necessidade de cada família cadastrada, sendo que em sua maioria, são atendidas pelo CRAS-Sul as famílias de baixa renda, sendo um dos requisitos da Lei Federal no 11.888 de 2008, que para beneficiar-se da assistência técnica gratuita para o projeto e a construção de moradia a família tenha renda em até 3 (três) salários mínimos, conforme disciplina o Art. $2^{\circ}$ da citada lei.

Ressalte-se que para o cadastramento das famílias pelo CRAS-Sul são levadas em considerações vários fatores e demandas sociais das famílias, e entre elas, as relacionadas a moradia. Como por exemplo se há presença de pessoa com deficiência, se algum membro da família é portador de doença grave, se faz uso de algum medicamento controlado, se a família fornece indícios de situação de insegurança alimentar entre outros. Como o próprio nome diz, o diagnóstico social das famílias contempla vários dados necessários para a prestação de assistência social às famílias e entre eles os relacionados a moradia. Cabendo-se reafirmar da importância da moradia para o bem social das famílias.

$\mathrm{Na}$ sede social do CRAS-Sul estabeleceu-se contato com os técnicos municipais que, puderam fornecer dados acerca das demandas em relação às condições habitacionais das famílias cadastradas, e o possível interesse e necessidade de receberem os benefícios propostos pela referida lei.

\subsection{Coleta de dados}

Os agentes públicos do Município de Teófilo Otoni, lotados no CRAS-Sul realizam frequentemente pesquisas com as famílias carentes da região, que integram atualmente banco de dados (documentos impressos) com cerca de 1250 famílias cadastradas nesta região. Nesta pesquisa, contém dados como número de pessoas residentes, rendimentos, participação em programas sociais, situação e particularidades da residência, dentre outros, descritos no Anexo A.

A partir dos dados obtidos no CRAS-Sul, (documentos impressos) selecionou-se 226 famílias cadastradas, as quais atendem aos requisitos estabelecidos na Lei Federal 11.888/08, ou seja, observando os requisitos referentes a ter renda familiar de até três salários mínimos, quantidade de cômodos, quartos por domicílio, qual o material utilizado no revestimento das paredes e piso das residências, informações sobre questões relacionadas ao bem estar das famílias como a localização em área de risco, acessibilidade às pessoas portadoras de necessidades especiais, acesso à energia elétrica, água canalizada, coleta de lixo, dentre outros delimitados na lei Federal objeto do estudo.

Além destas 226 famílias destes questionários realizados pelos agentes do CRAS-Sul, a pesquisa contou ainda com colaboração de 1 Assistente Social e 03 assistentes do mesmo CRAS-Sul. Sem ignorar a contribuição do Presidente da Câmara Municipal, Secretário Municipal da Habitação e Assistência Social, na fase inicial de levantamento dos dados, que contribuíram para o acesso a este banco de dados (documentos impressos) do CRAS-Sul. Todos os sujeitos estavam vinculados ao arranjo durante o período de aplicação do método de coleta de dados.

\section{Análise de dados}

\subsection{Perfil familiar}

Inicialmente na análise de dados, foram considerados os perfis das famílias pesquisadas de acordo com a Tabela 1. Os perfis pesquisados, levaram em consideração o percentual de faixa etária em função do ano de cadastro, gênero, grau de escolaridade e recebimento de bolsa família, a partir dos questionários fornecidos pelo CRAS-Sul. 
Tabela 1 - Perfil das famílias quando comparados faixa etária versus ano de cadastro, gênero, grau de escolaridade e recebimento de bolsa família.

\begin{tabular}{|c|c|c|c|c|c|c|c|c|}
\hline \multirow{2}{*}{$\begin{array}{l}\text { Ano de Cadastro no CRAS- } \\
\text { Sul }\end{array}$} & \multicolumn{8}{|c|}{ Ano de cadastro versus Faixa Etária } \\
\hline & \begin{tabular}{|c} 
De 15 a 24 \\
anos
\end{tabular} & $\begin{array}{c}\text { De } 25 \text { a } 34 \\
\text { anos }\end{array}$ & $\begin{array}{c}\text { De } 35 \text { a } 44 \\
\text { anos }\end{array}$ & $\begin{array}{c}\text { De } 45 \text { a } 54 \\
\text { anos }\end{array}$ & $\begin{array}{c}\text { De } 55 \text { a } 64 \\
\text { anos }\end{array}$ & \begin{tabular}{|c} 
De 65 a 74 \\
anos
\end{tabular} & $\begin{array}{c}\text { Acima de } \\
74 \text { anos }\end{array}$ & Total \\
\hline 2012 & $6,8 \%$ & $3,9 \%$ & $1,4 \%$ & $5,4 \%$ & & & - & $3,3 \%$ \\
\hline 2013 & $11,4 \%$ & $7,8 \%$ & $5,6 \%$ & $1,8 \%$ & & $18,2 \%$ & $14,3 \%$ & $6,6 \%$ \\
\hline 2014 & $4,5 \%$ & $5,9 \%$ & $6,9 \%$ & $3,6 \%$ & & $9,1 \%$ & - & $4,8 \%$ \\
\hline 2015 & $25,0 \%$ & $27,5 \%$ & $33,3 \%$ & $30,4 \%$ & $32,0 \%$ & $36,4 \%$ & $21,4 \%$ & $29,7 \%$ \\
\hline 2016 & $27,3 \%$ & $33,3 \%$ & $23,6 \%$ & $23,2 \%$ & $36,0 \%$ & $9,1 \%$ & $14,3 \%$ & $26,0 \%$ \\
\hline 2017 & $25,0 \%$ & $21,6 \%$ & $29,2 \%$ & $35,7 \%$ & $32,0 \%$ & $27,3 \%$ & $50,0 \%$ & $29,7 \%$ \\
\hline Total & $100,0 \%$ & $100,0 \%$ & $100,0 \%$ & $100,0 \%$ & $100,0 \%$ & $100,0 \%$ & $100,0 \%$ & $100,0 \%$ \\
\hline \multirow[t]{2}{*}{ Gênero } & \multicolumn{8}{|c|}{ Gênero versus Faixa Etária } \\
\hline & $\begin{array}{c}\text { De } 15 \text { a } 24 \\
\text { anos }\end{array}$ & $\begin{array}{c}\text { De } 25 \text { a } 34 \\
\text { anos }\end{array}$ & $\begin{array}{c}\text { De } 35 \text { a } 44 \\
\text { anos }\end{array}$ & $\begin{array}{c}\text { De } 45 \text { a } 54 \\
\text { anos }\end{array}$ & $\begin{array}{c}\text { De } 55 \text { a } 64 \\
\text { anos }\end{array}$ & $\begin{array}{c}\text { De } 65 \text { a } 74 \\
\text { anos }\end{array}$ & $\begin{array}{l}\text { Acima de } \\
74 \text { anos }\end{array}$ & Total \\
\hline Masculino & $2,3 \%$ & $15,7 \%$ & $11,1 \%$ & $12,5 \%$ & $12,0 \%$ & $36,4 \%$ & $21,4 \%$ & $12,5 \%$ \\
\hline Feminino & $97,7 \%$ & $84,3 \%$ & $88,9 \%$ & $87,5 \%$ & $88,0 \%$ & $63,6 \%$ & $78,6 \%$ & $87,5 \%$ \\
\hline Total & $100,0 \%$ & $100,0 \%$ & $100,0 \%$ & $100,0 \%$ & $100,0 \%$ & $100,0 \%$ & $100,0 \%$ & $100,0 \%$ \\
\hline \multirow{2}{*}{ Escolaridade } & \multicolumn{8}{|c|}{ Grau de Escolaridade versus Faixa Etária } \\
\hline & $\begin{array}{c}\text { De } 15 \text { a } 24 \\
\text { anos }\end{array}$ & $\begin{array}{c}\text { De } 25 \text { a } 34 \\
\text { anos }\end{array}$ & \begin{tabular}{|c|} 
De 35 a 44 \\
anos
\end{tabular} & $\begin{array}{c}\text { De } 45 \text { a } 54 \\
\text { anos }\end{array}$ & $\begin{array}{c}\text { De } 55 \text { a } 64 \\
\text { anos }\end{array}$ & \begin{tabular}{|c} 
De 65 a 74 \\
anos
\end{tabular} & $\begin{array}{c}\text { Acima de } \\
74 \text { anos }\end{array}$ & Total \\
\hline SE & & $5,9 \%$ & $8,3 \%$ & $5,4 \%$ & $16,0 \%$ & $72,7 \%$ & $57,1 \%$ & $11,7 \%$ \\
\hline EFI & $59,1 \%$ & $62,7 \%$ & $56,9 \%$ & $58,9 \%$ & $48,0 \%$ & $18,2 \%$ & $28,6 \%$ & $54,9 \%$ \\
\hline $\mathrm{EFC}$ & $4,5 \%$ & $3,9 \%$ & $13,9 \%$ & $21,4 \%$ & $32,0 \%$ & & $7,1 \%$ & $12,8 \%$ \\
\hline EMI & $25,0 \%$ & $19,6 \%$ & $16,7 \%$ & $5,4 \%$ & $4,0 \%$ & $9,1 \%$ & - & $13,9 \%$ \\
\hline EMC & $6,8 \%$ & $5,9 \%$ & $4,2 \%$ & $8,9 \%$ & & & $7,1 \%$ & $5,5 \%$ \\
\hline ESI & $4,5 \%$ & $2,0 \%$ & & & & & - & $1,1 \%$ \\
\hline Total & $100,0 \%$ & $100,0 \%$ & $100,0 \%$ & $100,0 \%$ & $100,0 \%$ & $100,0 \%$ & $100,0 \%$ & $100,0 \%$ \\
\hline \multicolumn{9}{|c|}{$\begin{array}{l}\text { Legenda - Sem escolaridade (SE), Ensino Fundamental Incompleto (EFI), Ensino Fundamental Completo (EFC), Ensino Médio Incompleto (EMI), } \\
\text { Ensino Médio Completo (EMC), Ensino Superior Incompleto (ESI) }\end{array}$} \\
\hline \multirow[t]{2}{*}{ Bolsa Família } & \multicolumn{8}{|c|}{ Bolsa Família versus Faixa Etária } \\
\hline & $\begin{array}{l}\text { De } 15 \text { a } 24 \\
\text { anos }\end{array}$ & $\begin{array}{c}\text { De } 25 \text { a } 34 \\
\text { anos }\end{array}$ & $\begin{array}{c}\text { De } 35 \text { a } 44 \\
\text { anos }\end{array}$ & $\begin{array}{c}\text { De } 45 \text { a } 54 \\
\text { anos }\end{array}$ & $\begin{array}{c}\text { De } 55 \text { a } 64 \\
\text { anos }\end{array}$ & $\begin{array}{c}\text { De } 65 \text { a } 74 \\
\text { anos }\end{array}$ & $\begin{array}{l}\text { Acima de } \\
74 \text { anos }\end{array}$ & Total \\
\hline Sim & $40,9 \%$ & $47,1 \%$ & $62,5 \%$ & $46,4 \%$ & $60,0 \%$ & $18,2 \%$ & $21,4 \%$ & $48,7 \%$ \\
\hline Não & $59,1 \%$ & $52,9 \%$ & $37,5 \%$ & $53,6 \%$ & $40,0 \%$ & $81,8 \%$ & $78,6 \%$ & $51,3 \%$ \\
\hline Total & $100,0 \%$ & $100,0 \%$ & $100,0 \%$ & $100,0 \%$ & $100,0 \%$ & $100,0 \%$ & $100,0 \%$ & $100,0 \%$ \\
\hline
\end{tabular}

Fonte: Pesquisa no banco de dados do CRAS-Sul (2017)

- Ano de cadastro no CRAS-Sul versus Faixa Etária: observa-se na Tabela 1 que a coleta de dados realizada pelo CRAS-Sul intensificou-se a partir do ano de 2015, somando 85,4\% nos três últimos anos de cadastro (período 2015 a 2017 na coluna total da Tabela 1). Os dados permitiram observar que os moradores, em sua maioria, têm idade superior aos 55 anos, com os maiores percentuais acima dos 74 anos de idade, quando analisados os cadastros realizados nos anos de 2012 a 2017.

- Gênero versus Faixa Etária: quanto o gênero, a partir da análise dos questionários fornecidos no CRAS-Sul identificou-se que as pessoas que integram as famílias em sua maioria são do gênero feminino com um total de $87,5 \%$ contra 12,5\% para o gênero masculino. Ainda em relação ao gênero, a maior concentração do gênero feminino das famílias está na faixa etária entre 15 a 24 anos $(97,7 \%)$, já a maior concentração do gênero masculino está na faixa etária entre 65 a 74 anos $(36,4 \%)$.

- Escolaridade versus Faixa Etária: quanto à escolaridade, quando observado o total das famílias, 54,9\% possuem o Ensino Fundamental Incompleto (EFI). Os dados das famílias que possuem a menor formação escolar (SE) estão concentrados entre a faixa de 65 a 74 anos de idade $(72,7 \%)$ e a maior formação escolar (ESI) está concentrada entre a faixa de 15 a 24 anos 
de idade (4,5\%). Considerando que a maioria dos perfis das famílias são do gênero feminino e que a concentração também se encontra na mesma faixa de 15 a 24 anos de idade, deduz que a população feminina, mesmo diante das dificuldades, vem evidenciando maiores esforços para obtenção de melhor nível educacional.

- Bolsa família versus Faixa Etária: no tocante aos beneficiários do programa social bolsa família, 48,7\% das famílias estão cadastrados neste programa e a maior concentração dos beneficiários está na faixa etária de 35 aos 44 anos de idade $(62,5 \%)$.

A Tabela 2 mostra o perfil das famílias levando em consideração o bairro versus o percentual relativo à renda das famílias participantes da pesquisa.

Tabela 2 - Perfil das famílias em relação ao bairro versus renda total.

\begin{tabular}{|c|c|c|c|c|c|c|c|c|}
\hline Bairros & $\begin{array}{c}\text { De 0 a } \\
\text { R\$ 234,00 }\end{array}$ & \begin{tabular}{|c} 
De \\
R\$ 235,00 a \\
R\$ 470,00 \\
\end{tabular} & \begin{tabular}{|c} 
De \\
R\$ 471,00 a \\
$\mathrm{R} \$ 937,00$ \\
\end{tabular} & \begin{tabular}{|c|c} 
De \\
$\mathbf{R} \$ 938,00$ a \\
$\mathbf{R} \$ 1407,00$ \\
\end{tabular} & \begin{tabular}{|c} 
De \\
R\$ 1408,00 a \\
R\$1877,00 \\
\end{tabular} & \begin{tabular}{|c} 
De \\
R\$ 1878,00 a \\
R\$2347,00 \\
\end{tabular} & \begin{tabular}{|c} 
De \\
R\$ 2348,00 a \\
R\$2811,00 \\
\end{tabular} & Total \\
\hline Cidade Nova & $13,8 \%$ & $10,3 \%$ & $13,9 \%$ & & $15,4 \%$ & $50,0 \%$ & - & $12,8 \%$ \\
\hline Conjunto Paulo Freire & & $1,7 \%$ & & - & & - & - & $0,4 \%$ \\
\hline Frei Júlio & $12,5 \%$ & $10,3 \%$ & $9,3 \%$ & $25,0 \%$ & $23,1 \%$ & - & - & $11,4 \%$ \\
\hline Jardim São Paulo & $13,8 \%$ & $20,7 \%$ & $6,5 \%$ & $25,0 \%$ & $30,8 \%$ & $50,0 \%$ & - & $13,6 \%$ \\
\hline São Benedito & $11,3 \%$ & $13,8 \%$ & $15,7 \%$ & - & - & - & - & $12,5 \%$ \\
\hline Solidariedade & - & - & - & - & - & - & $25,0 \%$ & $0,4 \%$ \\
\hline Tancredo Neves & $1,3 \%$ & $1,7 \%$ & $1,9 \%$ & - & - & - & - & $1,5 \%$ \\
\hline Taquara & $18,8 \%$ & $15,5 \%$ & $20,4 \%$ & $12,5 \%$ & $15,4 \%$ & & - & $17,9 \%$ \\
\hline Vila Barreiros & $10,0 \%$ & $15,5 \%$ & $11,1 \%$ & $25,0 \%$ & $7,7 \%$ & - & $75,0 \%$ & $12,8 \%$ \\
\hline Vila Esperança & $13,8 \%$ & $6,9 \%$ & $14,8 \%$ & - & - & - & - & $11,4 \%$ \\
\hline Vila Jacaré & $1,3 \%$ & $3,4 \%$ & $5,6 \%$ & - & $7,7 \%$ & - & - & $3,7 \%$ \\
\hline Vila Progresso & $1,3 \%$ & - & $0,9 \%$ & $12,5 \%$ & - & - & - & $1,1 \%$ \\
\hline Vilinha & $2,5 \%$ & - & - & - & - & - & - & $0,7 \%$ \\
\hline Total & $100,0 \%$ & $100,0 \%$ & $100,0 \%$ & $100,0 \%$ & $100,0 \%$ & $100,0 \%$ & $100,0 \%$ & $100,0 \%$ \\
\hline
\end{tabular}

Fonte: Pesquisa no banco de dados do CRAS-Sul (2017)

- Perfil das famílias em relação aos bairros versus renda total familiar: a partir da Tabela 2 constata-se que nas menores faixas de renda de 0 a $\mathrm{R} \$ 937,00$, ou seja, inferior ao salário mínimo vigente no ano de 2017, merecem destaques os bairros: Taquara, Jardim São Paulo e São Benedito. O que se observa, de modo geral, é que existe nos bairros analisados uma faixa de renda muito baixa, o que sugere prioridade de inserção nestes bairros dos benefícios concedidos na lei em epígrafe.

Outra análise a ser considerada refere-se ao perfil das famílias levando em consideração bairro versus tempo de moradia, que está determinado na Tabela 3. 
Tabela 3 - Perfil das famílias em relação aos bairros versus tempo de moradia no bairro.

\begin{tabular}{|c|c|c|c|c|c|c|}
\hline Bairros & Abaixo de 10 anos & De 11 a 20 anos & De 21 a 30 anos & De 31 a 40 anos & Acima de 40 anos & Total \\
\hline Cidade Nova & $13,9 \%$ & $18,6 \%$ & $6,1 \%$ & $15,4 \%$ & - & $12,8 \%$ \\
\hline Conjunto Paulo Freire & $0,6 \%$ & & & & - & $0,4 \%$ \\
\hline Frei Júlio & $10,3 \%$ & $20,9 \%$ & $6,1 \%$ & $15,4 \%$ & $5,3 \%$ & $11,4 \%$ \\
\hline Jardim São Paulo & $15,2 \%$ & $7,0 \%$ & $9,1 \%$ & $15,4 \%$ & $21,1 \%$ & $13,6 \%$ \\
\hline São Benedito & $13,9 \%$ & $11,6 \%$ & $6,1 \%$ & $23,1 \%$ & $5,3 \%$ & $12,5 \%$ \\
\hline Solidariedade & - & - & $3,0 \%$ & - & - & $0,4 \%$ \\
\hline Tancredo Neves & $1,2 \%$ & - & $3,0 \%$ & & $5,3 \%$ & $1,5 \%$ \\
\hline Taquara & $18,8 \%$ & $7,0 \%$ & $27,3 \%$ & $7,7 \%$ & $26,3 \%$ & $17,9 \%$ \\
\hline Vila Barreiros & $10,9 \%$ & $23,3 \%$ & $15,2 \%$ & $7,7 \%$ & $5,3 \%$ & $12,8 \%$ \\
\hline Vila Esperança & $9,1 \%$ & $7,0 \%$ & $21,2 \%$ & $7,7 \%$ & $26,3 \%$ & $11,4 \%$ \\
\hline Vila Jacaré & $4,2 \%$ & $2,3 \%$ & - & $7,7 \%$ & $5,3 \%$ & $3,7 \%$ \\
\hline Vila Progresso & $1,2 \%$ & $2,3 \%$ & - & - & - & $1,1 \%$ \\
\hline Vilinha & $0,6 \%$ & - & $3,0 \%$ & - & - & $0,7 \%$ \\
\hline Total & $100,0 \%$ & $100,0 \%$ & $100,0 \%$ & $100,0 \%$ & $100,0 \%$ & $100,0 \%$ \\
\hline
\end{tabular}

Fonte: Pesquisa no banco de dados do CRAS-Sul (2017).

- Perfil das famílias em relação ao bairro versus tempo de moradia no bairro: conforme Tabela 3 , entre os bairros que possuem os moradores mais antigos destacam-se: Jardim São Paulo e Taquara. Quando relacionados esses dados com os dados da Tabela 2, é possível observar que as famílias mais carentes no que tange a renda de até $\mathrm{R} \$ 937,00$ (salário mínimo vigente no ano de 2017) e tempo de moradia, que os bairros com baixa renda também são aqueles com o maior tempo de moradia. Vale destacar que a baixa renda das famílias pesquisadas, pode representar um fator de exclusão social nos bairros pesquisados, além disso o tempo de moradia indica que os moradores dos bairros mais carentes são pessoas mais idosas.

\subsection{Situação dos bairros destas famílias}

Em um segundo momento a análise dos dados do CRAS-Sul utilizou tabelas cruzadas envolvendo as seguintes variáveis: domicílios em área risco, acesso a água canalizada, tipos de esgotos sanitários, coleta de lixo, difícil acesso geográfico e área de violência. A Tabela 4 apresenta o perfil das moradias considerando os bairros e os percentuais relativos aos domicílios que possuem ou não área de risco e acesso à água canalizada.

Tabela 4 - Perfil das moradias em relação aos bairros versus área de risco e água canalizada.

\begin{tabular}{|c|c|c|c|c|c|c|}
\hline \multirow[t]{2}{*}{ Bairros } & \multicolumn{3}{|c|}{ \% Domicílios em área de risco } & \multicolumn{3}{|c|}{ \% em acesso a água canalizada } \\
\hline & Sim & Não & Total & Sim & Não & Total \\
\hline Cidade Nova & $5,7 \%$ & $94,3 \%$ & $100,0 \%$ & $100,0 \%$ & - & $100,0 \%$ \\
\hline Conjunto Paulo Freire & - & $100,0 \%$ & $100,0 \%$ & $100,0 \%$ & - & $100,0 \%$ \\
\hline Frei Júlio & - & $100,0 \%$ & $100,0 \%$ & $100,0 \%$ & - & $100,0 \%$ \\
\hline Jardim São Paulo & $5,4 \%$ & $94,6 \%$ & $100,0 \%$ & $100,0 \%$ & - & $100,0 \%$ \\
\hline São Benedito & - & $100,0 \%$ & $100,0 \%$ & $100,0 \%$ & - & $100,0 \%$ \\
\hline Solidariedade & - & $100,0 \%$ & $100,0 \%$ & $100,0 \%$ & - & $100,0 \%$ \\
\hline Tancredo Neves & - & $100,0 \%$ & $100,0 \%$ & $100,0 \%$ & - & $100,0 \%$ \\
\hline Taquara & $4,1 \%$ & $95,9 \%$ & $100,0 \%$ & $100,0 \%$ & - & $100,0 \%$ \\
\hline Vila Barreiros & - & $100,0 \%$ & $100,0 \%$ & $100,0 \%$ & - & $100,0 \%$ \\
\hline Vila Esperança & $9,7 \%$ & $90,3 \%$ & $100,0 \%$ & $100,0 \%$ & - & $100,0 \%$ \\
\hline Vila Jacaré & $10,0 \%$ & $90,0 \%$ & $100,0 \%$ & $100,0 \%$ & - & $100,0 \%$ \\
\hline Vila Progresso & - & $100,0 \%$ & $100,0 \%$ & $100,0 \%$ & - & $100,0 \%$ \\
\hline Vilinha & - & $100,0 \%$ & $100,0 \%$ & $100,0 \%$ & - & $100,0 \%$ \\
\hline
\end{tabular}


- Perfil das moradias em relação aos bairros versus área de risco e água canalizada: observando a Tabela 4 é importante destacar que todos os domicílios possuem água encanada.

Todavia, apenas $10 \%$ das famílias que residem no bairro Vila Jacaré, ao responderem o questionário aplicados pelo CRAS-Sul, consideraram que residiam em área de risco. Consideram-se áreas de riscos as moradias que por baixa ou nenhuma assistência técnica pública, foram edificadas às margens ou em nível inferior a rodovia de alto tráfego (Figura 2).

Figura 2 - Moradias abaixo do nível da Rua na Vila Jacaré.

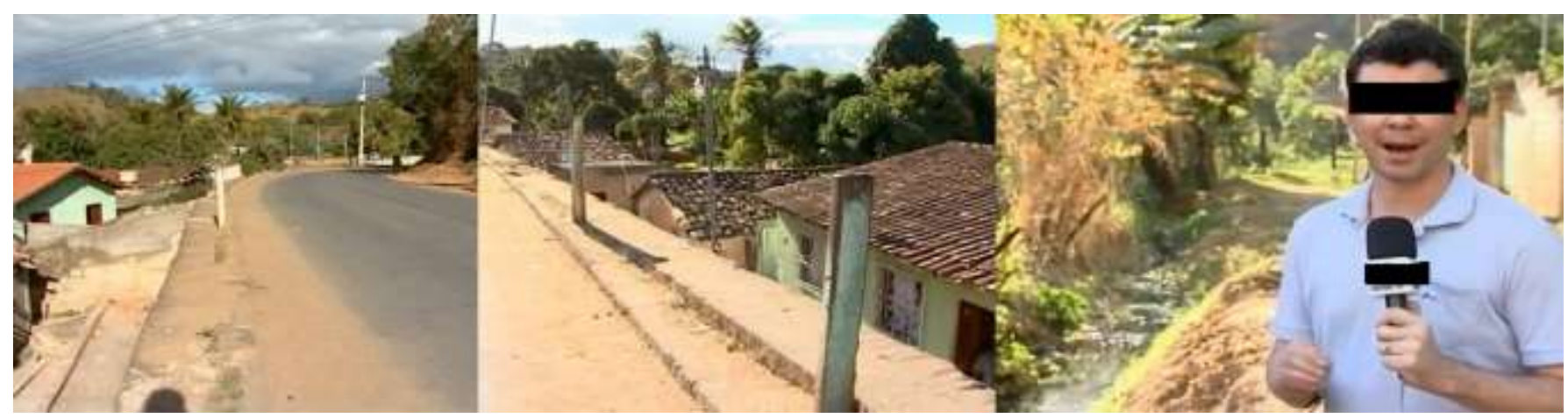

Fonte: G1 Vales MG - MG Inter TV 2ª Edição (2013)

A Figura 2 ilustra um exemplo da construção de moradias abaixo do nível da rua e próximo de córregos, na Vila Jacaré $(\mathrm{G} 1,2013)$. Essas residências estão passíveis de desmoronamentos, queda de veículos, bem como de enchentes provenientes do córrego que atravessa o bairro a céu aberto.

Outra realidade dos bairros pesquisados é a edificação de alicerces em terrenos sem a devida sondagem do solo, sem muro de arrimo ou propenso a erosões e graves 'voçorocas' ou 'boçorocas'. Destarte, no período das chuvas, podem ocorrer deslizamentos de terra vindo a descobrir as fundações, podendo o alicerce ficar descalçado, o que futuramente pode provocar o desabamento da residência.

A Figura 3, mostra outra situação em que as edificações são realizadas ao lado de barrancos, também sem muro de arrimo, que no período chuvoso, há movimento da terra vindo a soterrar a edificação. O Bairro Jardim São Paulo, que apresenta 5,4\% de área de risco, representa o processo de ocupação de forma irregular (sem assistência técnica) ou clandestina (sem autorização do poder Público) na parte mais plana, baixa e ao leito do córrego, que pela ausência de infraestrutura compatível, agravam em situações de enchentes ou movimentos massa. 
Figura 3 - Área de risco Bairro Cidade Nova

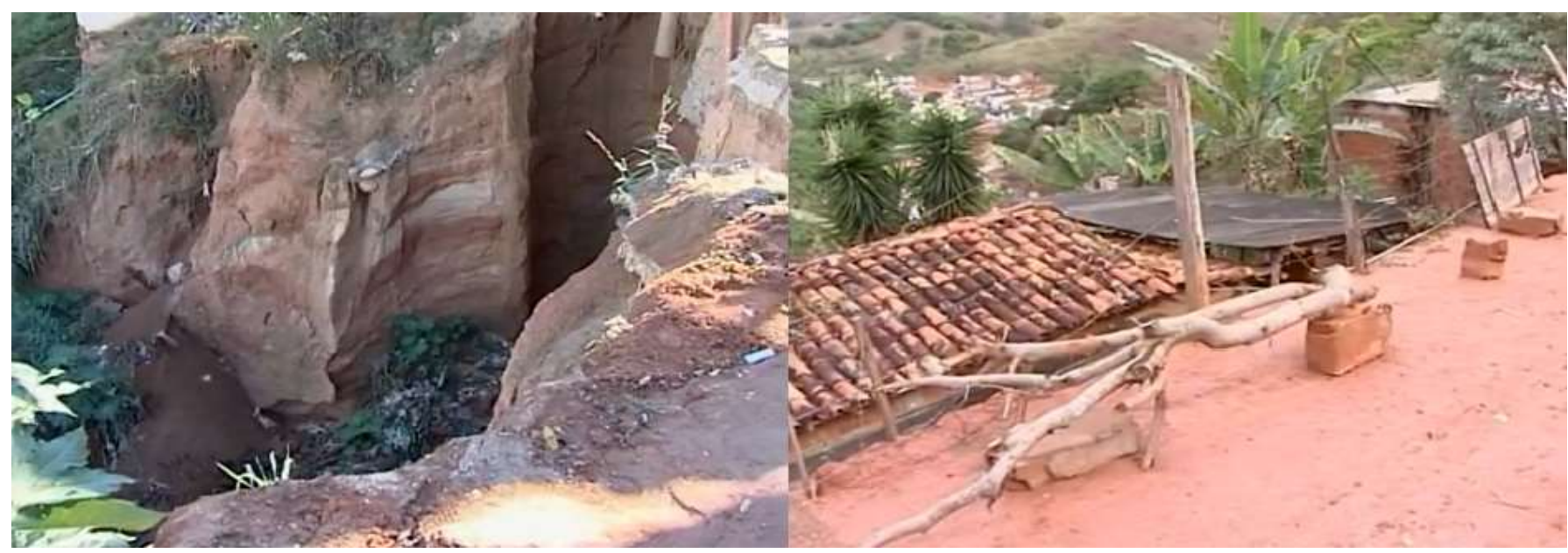

Fonte: G1 Vales MG - MG Inter TV 2ª Edição (2013)

A prova da necessidade de assistência técnica, extrai-se da comparação do Bairro Vila Esperança e o conjunto Paulo Freire, que são limítrofes (Figura 4). No conjunto habitacional Paulo Freire, as casas, edificadas com as devidas orientações técnicas, detêm $0 \%$ de área de risco. Por outro lado, a região mais antiga (Vila Esperança), detém 9,7\% de área de risco.

Figura 4 - Vila Esperança e Construção Conjunto Paulo Freire.

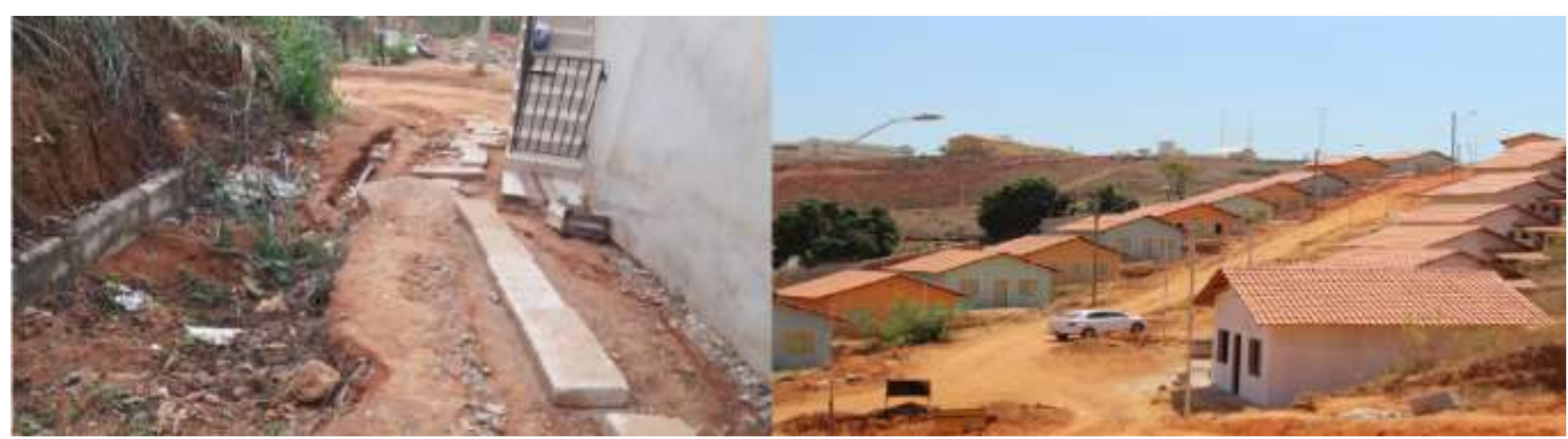

Fonte: Rádio Teófilo Otoni (2016)

O Bairro Cidade Nova, apesar de ser um bairro novo, cerca de 10 a $20 \%$ do tempo existencial da cidade Teófilo Otoni, isto é, que concentra moradores com até 20 anos de residência no local, ainda detém um elevado nível, pois cerca de 5,7\% das moradias estão situadas em área de risco. Tal Fato que poderia ser evitado, caso houvesse os devidos acompanhamentos de capacitação técnica, evitando as edificações à beira de barrancos desprotegidos.

A Tabela 5 mostra o perfil das moradias levando em consideração os bairros e os percentuais relativos aos tipos de esgotos sanitários. 
Tabela 5 - Bairros versus tipos de esgotos sanitários.

\begin{tabular}{|c|c|c|c|c|c|}
\hline \multirow[t]{2}{*}{ Bairros } & \multicolumn{5}{|c|}{ Esgoto Sanitário } \\
\hline & Rede Esgoto & Fossa Rudimentar & Fossa Séptica & Direto Vala & Total \\
\hline Cidade Nova & $68,6 \%$ & $14,3 \%$ & $17,1 \%$ & - & $100,0 \%$ \\
\hline Conjunto Paulo Freire & $100,0 \%$ & - & - & - & $100,0 \%$ \\
\hline Frei Júlio & $96,8 \%$ & - & $3,2 \%$ & - & $100,0 \%$ \\
\hline Jardim São Paulo & $97,3 \%$ & $2,7 \%$ & - & - & $100,0 \%$ \\
\hline São Benedito & $35,3 \%$ & $26,5 \%$ & $38,2 \%$ & - & $100,0 \%$ \\
\hline Solidariedade & $100,0 \%$ & - & - & - & $100,0 \%$ \\
\hline Tancredo Neves & $50,0 \%$ & - & $50,0 \%$ & - & $100,0 \%$ \\
\hline Taquara & $83,7 \%$ & $8,2 \%$ & $6,1 \%$ & $2,0 \%$ & $100,0 \%$ \\
\hline Vila Barreiros & $94,3 \%$ & - & - & $5,7 \%$ & $100,0 \%$ \\
\hline Vila Esperança & $93,5 \%$ & - & $6,5 \%$ & - & $100,0 \%$ \\
\hline Vila Jacaré & $90,0 \%$ & - & $10,0 \%$ & - & $100,0 \%$ \\
\hline Vila Progresso & $100,0 \%$ & - & - & - & $100,0 \%$ \\
\hline Vilinha & $100,0 \%$ & - & - & - & $100,0 \%$ \\
\hline
\end{tabular}

Fonte: Pesquisa no banco de dados do CRAS-Sul (2017)

- Bairros versus tipos de esgotos sanitários: nos termos da Lei de $n^{\circ}$ 6.626/13, que instituiu o Plano Municipal de Saneamento Básico destinado à execução dos serviços de obras de abastecimento de água e esgotamento sanitário no município e a Lei Municipal de no 5.892/08, que dispõe o Plano Diretor, em seu Art. 16, que determina o Plano Municipal de Saneamento básico de Teófilo Otoni, os dados corroboram a necessidade da assistência técnica pública.

De acordo com a Tabela 5, observou-se que o conjunto habitacional Paulo Freire, detém 100\% de esgoto sanitário canalizado, já os bairros mais carentes, apresentam índices baixos de não canalização do esgoto e que lançam dejetos diretamente em vala, como os Bairros Vila Barreiros (5,7\%) e Taquara (2\%). Posteriormente, o Bairro São Benedito, pois ainda mantém moradias com $26,5 \%$ de fossa rudimentar e $38,2 \%$ com fossa séptica, ou seja, quase $70 \%$ sem atendimento de coleta canalizada de esgoto sanitário.

Na sequência das prioridades, o bairro Tancredo Neves, que somente a metade (50\%), são atendidos por esgotamento canalizado. Posteriormente, os que ainda detém percentual sem atendimento sanitário, estão os Bairros Cidade Nova (31,4\%), Vila Jacaré (10\%), Vila Esperança (6,5\%), Jardim São Paulo (2,7\% de fossa rudimentar) e Frei Júlio com 3,2\% de fossa séptica.

A Tabela 6 mostra o perfil dos domicílios levando em consideração a relação dos bairros versus a coleta de lixo, localizados em difícil acesso geográfico e em área de violência. A área de violência é considerada como aquela onde existe a possibilidade do morador, em visão individual ou coletiva, sofrer um dano futuro que promova um desequilíbrio ao direito à vida (Schramm \& Castiel, 1992). 
Tabela 6 - Perfil dos domicílios nos bairros versus coleta de lixo, localizados em difícil acesso geográfico e situados em área de violência.

\begin{tabular}{|c|c|c|c|c|c|c|c|c|c|}
\hline \multirow[t]{2}{*}{ Bairros } & \multicolumn{3}{|c|}{ Coleta lixo } & \multicolumn{3}{|c|}{ Domicílio DAG } & \multicolumn{3}{|c|}{ Domicílio AV } \\
\hline & Sim & Não & Total & Sim & Não & Total & Sim & Não & Total \\
\hline Cidade Nova & $97,1 \%$ & $2,9 \%$ & $100,0 \%$ & $2,9 \%$ & $97,1 \%$ & $100,0 \%$ & $8,6 \%$ & $91,4 \%$ & $100,0 \%$ \\
\hline Conjunto Paulo Freire & $100,0 \%$ & - & $100,0 \%$ & - & $100,0 \%$ & $100,0 \%$ & - & $100,0 \%$ & $100,0 \%$ \\
\hline Frei Júlio & $100,0 \%$ & - & $100,0 \%$ & - & $100,0 \%$ & $100,0 \%$ & $12,9 \%$ & $87,1 \%$ & $100,0 \%$ \\
\hline Jardim São Paulo & $94,6 \%$ & $5,4 \%$ & $100,0 \%$ & $2,7 \%$ & $97,3 \%$ & $100,0 \%$ & $5,4 \%$ & $94,6 \%$ & $100,0 \%$ \\
\hline São Benedito & $100,0 \%$ & - & $100,0 \%$ & $2,9 \%$ & $97,1 \%$ & $100,0 \%$ & $5,9 \%$ & $94,1 \%$ & $100,0 \%$ \\
\hline Solidariedade & $100,0 \%$ & - & $100,0 \%$ & - & $100,0 \%$ & $100,0 \%$ & - & $100,0 \%$ & $100,0 \%$ \\
\hline Tancredo Neves & $100,0 \%$ & - & $100,0 \%$ & - & $100,0 \%$ & $100,0 \%$ & - & $100,0 \%$ & $100,0 \%$ \\
\hline Taquara & $91,8 \%$ & $8,2 \%$ & $100,0 \%$ & $2,0 \%$ & $98,0 \%$ & $100,0 \%$ & $6,1 \%$ & $93,9 \%$ & $100,0 \%$ \\
\hline Vila Barreiros & $88,6 \%$ & $11,4 \%$ & $100,0 \%$ & - & $100,0 \%$ & $100,0 \%$ & $5,7 \%$ & $94,3 \%$ & $100,0 \%$ \\
\hline Vila Esperança & $100,0 \%$ & - & $100,0 \%$ & - & $100,0 \%$ & $100,0 \%$ & $6,5 \%$ & $93,5 \%$ & $100,0 \%$ \\
\hline Vila Jacaré & $90,0 \%$ & $10,0 \%$ & $100,0 \%$ & - & $100,0 \%$ & $100,0 \%$ & - & $100,0 \%$ & $100,0 \%$ \\
\hline Vila Progresso & $100,0 \%$ & - & $100,0 \%$ & - & $100,0 \%$ & $100,0 \%$ & - & $100,0 \%$ & $100,0 \%$ \\
\hline Vilinha & $100,0 \%$ & - & $100,0 \%$ & - & $100,0 \%$ & $100,0 \%$ & - & $100,0 \%$ & $100,0 \%$ \\
\hline
\end{tabular}

Legenda: difícil acesso geográfico - DAG; área de violência - AV.

Fonte: Pesquisa no banco de dados do CRAS-Sul (2017)

- Perfil dos domicílios nos bairros versus coleta de lixo, localizados em difícil acesso geográfico e situados em área de violência: conforme Tabela 6, nas informações dos dados diagnosticados, visualiza-se que os bairros de moradores com menor renda familiar como o Frei Júlio, que quase $70 \%$ das famílias recebem menos que 1,5 salários mínimos (vigentes no ano de 2017) como renda total mensal (Tabela 2), a incidência de violência é maior (12,9\%). Na sequência, ainda observando pelo aspecto das moradias localizadas em área de violência, está o bairro Cidade Nova $(8,6 \%)$, que por sua vez possui 5,7\% de área de risco (Tabela 4) e cerca de 55\% com renda familiar total inferior à 2 salários mínimos mensais (Tabela 2), além de concorrer com o Bairro São Benedito, ao se comparar o índice que mede a dificuldade de acesso geográfico a cada bairro, registrando $2,9 \%$.

Os resultados que refletem a ausência da coleta de lixo podem estar correlacionados à dificuldade ao acesso geográfico ou área de risco ou área de violência. Fato que pode ser observado nos índices de ausência da devida coleta, apresentados nos Bairros Vila Barreiros (11,4\% sem coleta de lixo versus 5,7\% área de violência), Taquara (8,2\% sem coleta de lixo versus $2 \%$ área difícil acesso geográfico versus $6,1 \%$ área de violência).

A análise da situação das residências no bairro quanto à presença de medidor individual de energia e tipo de residência está apresentada na Tabela 7. Descreve-se, assim, o perfil das residências levando em consideração os bairros e os tipos de moradia e individualização dos medidores de energia. 
Tabela 7 - Perfil das residências nos bairros versus tipo de moradia e presença de medidor energia individual.

\begin{tabular}{l|r|r|r|r|r|r|r}
\hline \multirow{2}{*}{ Bairros } & \multicolumn{3}{c|}{ Tipo de Residência } & \multicolumn{3}{c}{ Medidor Energia Individual } \\
\cline { 2 - 7 } & Alugada & Cedida & Própria & Total & \multicolumn{1}{l}{ Sim } & \multicolumn{1}{c}{ Não } & \\
\hline Cidade Nova & $8,6 \%$ & $14,3 \%$ & $77,1 \%$ & $100,0 \%$ & $100,0 \%$ & - & $100,0 \%$ \\
Conjunto Paulo Freire & - & - & $100,0 \%$ & $100,0 \%$ & $100,0 \%$ & - & $100,0 \%$ \\
Frei Júlio & $16,1 \%$ & $6,5 \%$ & $77,4 \%$ & $100,0 \%$ & $96,8 \%$ & $3,2 \%$ & $100,0 \%$ \\
Jardim São Paulo & $10,8 \%$ & $18,9 \%$ & $70,3 \%$ & $100,0 \%$ & $97,3 \%$ & $2,7 \%$ & $100,0 \%$ \\
São Benedito & $5,9 \%$ & $17,6 \%$ & $76,5 \%$ & $100,0 \%$ & $100,0 \%$ & - & $100,0 \%$ \\
Solidariedade & $100,0 \%$ & - & - & $100,0 \%$ & $100,0 \%$ & - & $100,0 \%$ \\
Tancredo Neves & $25,0 \%$ & $25,0 \%$ & $50,0 \%$ & $100,0 \%$ & $100,0 \%$ & - & $100,0 \%$ \\
Taquara & $2,0 \%$ & $10,2 \%$ & $87,8 \%$ & $100,0 \%$ & $100,0 \%$ & - & $100,0 \%$ \\
Vila Barreiros & $17,1 \%$ & $11,4 \%$ & $71,4 \%$ & $100,0 \%$ & $94,3 \%$ & $5,7 \%$ & $100,0 \%$ \\
Vila Esperança & $29,0 \%$ & $25,8 \%$ & $45,2 \%$ & $100,0 \%$ & $96,8 \%$ & $3,2 \%$ & $100,0 \%$ \\
Vila Jacaré & $10,0 \%$ & $20,0 \%$ & $70,0 \%$ & $100,0 \%$ & $100,0 \%$ & - & $100,0 \%$ \\
Vila Progresso & $33,3 \%$ & - & $66,7 \%$ & $100,0 \%$ & $100,0 \%$ & - & $100,0 \%$ \\
Vilinha & - & - & $100,0 \%$ & $100,0 \%$ & $100,0 \%$ & - & $100,0 \%$ \\
\hline
\end{tabular}

Fonte: Pesquisa no banco de dados do CRAS-Sul (2017).

- Perfil das residências nos bairros versus \% tipo de moradia ou presença de medidor energia individual: conforme a Tabela 7 o Conjunto Paulo Freire, por ser um conjunto habitacional, apesar de serem financiadas, são todas consideradas próprias $(100 \%)$. As moradias alugadas situam-se à margem da prioridade legal, pois comumente os residentes não desejam realizar investimentos em imóveis que não lhes pertence, salvo a construção ou melhoria de banheiros.

O poder público pode intervir nos bairros das residências alugadas ou cedidas, quando se trata de ações externas às moradias como coleta de lixo, construção da canalização de esgotamento sanitário, elidir risco, violência e outros similares.

Tendo por base o benefício da lei em comento, observa-se que a maior incidência de energia compartilhada estão em moradias cedidas ou alugadas, como nos Bairros Vila Barreiros (5,7\%), que possui 17,1\% de moradias alugadas e 11,4\% de residências cedidas; Bairro Vila Esperança com 3,2\% de energia compartilhada, conquanto 29,0\% de famílias com residências locadas e cedidas com o percentual de 25,8\%; O Bairro Frei Júlio, que possui alta concentração de baixa renda, ainda detém, $3,2 \%$ de energia compartilhada no patamar 16,1\% de residências alugadas e 6,5\% cedidas e por último o Bairro Jardim São Paulo, com 2,7\% de moradias com divisão do padrão de energia em 10,8\% das residências em aluguel e 18,9\% das moradias cedidas.

A Tabela 8 mostra o perfil das moradias levando em consideração os bairros e os percentuais relativos ao número total de cômodos e acessibilidade.

- Perfil das moradias em relação aos Bairros versus tipo número de cômodos e acessibilidade: observando a Tabela 8, no tocante à acessibilidade, corrobora a necessidade de assistência técnica nas edificações e planejamento habitacional. Observa-se que o conjunto habitacional Paulo Freire, detém 100\% de moradias com acessibilidade, ao contrário dos planejamentos insuficientes nos Bairros com famílias enquadradas na menor faixa de renda (Tabela 3) que detém elevados índices de ausência de domicílios com a acessibilidade aos portadores de deficiência, como as moradias dos Bairros Solidariedade (100\%); Vila Progresso (100\%); Vila Esperança (83,9\%); Cidade Nova (80\%) e assim sucessivamente.

Com base no que é citado na Lei de $n^{\circ}$ 5.892/08, que dispõe o Plano Diretor Urbano de Teófilo Otoni, especialmente em seu Art. 28, que assegura o foco ao direito à moradia em condições adequadas e determina a política habitacional, levam a entender que os dados indicam a maior concentração dos domicílios com 4 a 6 cômodos, comumente compostos, por dois quartos, sala, cozinha e banheiro. 
Tabela 8 - Perfil das moradias em relação aos Bairros versus tipo número de cômodos e acessibilidade.

\begin{tabular}{|c|c|c|c|c|c|c|c|}
\hline \multirow[t]{2}{*}{ Bairros } & \multicolumn{4}{|c|}{ Número Total Cômodos } & \multicolumn{3}{|c|}{ Domicílio com acessibilidade de locomoção } \\
\hline & De 1 a 3 cômodos & De 4 a 6 cômodos & $\begin{array}{c}\text { Acima de } 7 \\
\text { cômodos }\end{array}$ & Total & Sim & Não & Total \\
\hline Cidade Nova & $37,1 \%$ & $54,3 \%$ & $8,6 \%$ & $100,0 \%$ & $20,0 \%$ & $80,0 \%$ & $100,0 \%$ \\
\hline Conjunto Paulo Freire & - & $100,0 \%$ & - & $100,0 \%$ & $100,0 \%$ & - & $100,0 \%$ \\
\hline Frei Júlio & $9,7 \%$ & $77,4 \%$ & $12,9 \%$ & $100,0 \%$ & $29,0 \%$ & $71,0 \%$ & $100,0 \%$ \\
\hline Jardim São Paulo & $18,9 \%$ & $62,2 \%$ & $18,9 \%$ & $100,0 \%$ & $27,0 \%$ & $73,0 \%$ & $100,0 \%$ \\
\hline São Benedito & $14,7 \%$ & $79,4 \%$ & $5,9 \%$ & $100,0 \%$ & $32,4 \%$ & $67,6 \%$ & $100,0 \%$ \\
\hline Solidariedade & - & $100,0 \%$ & - & $100,0 \%$ & - & $100,0 \%$ & $100,0 \%$ \\
\hline Tancredo Neves & $25,0 \%$ & $75,0 \%$ & - & $100,0 \%$ & $25,0 \%$ & $75,0 \%$ & $100,0 \%$ \\
\hline Taquara & $18,4 \%$ & $57,1 \%$ & $24,5 \%$ & $100,0 \%$ & $32,7 \%$ & $67,3 \%$ & $100,0 \%$ \\
\hline Vila Barreiros & $17,1 \%$ & $57,1 \%$ & $25,7 \%$ & $100,0 \%$ & $31,4 \%$ & $68,6 \%$ & $100,0 \%$ \\
\hline Vila Esperança & $22,6 \%$ & $77,4 \%$ & - & $100,0 \%$ & $16,1 \%$ & $83,9 \%$ & $100,0 \%$ \\
\hline Vila Jacaré & - & $80,0 \%$ & $20,0 \%$ & $100,0 \%$ & $20,0 \%$ & $80,0 \%$ & $100,0 \%$ \\
\hline Vila Progresso & $66,7 \%$ & $33,3 \%$ & - & $100,0 \%$ & - & $100,0 \%$ & $100,0 \%$ \\
\hline Vilinha & - & $100,0 \%$ & - & $100,0 \%$ & $50,0 \%$ & $50,0 \%$ & $100,0 \%$ \\
\hline
\end{tabular}

Fonte: Pesquisa no banco de dados do CRAS-Sul (2017)

Em caso desta variável, utilizando como parâmetro prioritário de assistência técnica, seriam beneficiadas as moradias que possuem 1 a 3 cômodos. Em ordem decrescente temos os seguintes Bairros: Vila Progresso (66,7\%); Cidade Nova (37,1\%); Tancredo Neves (25\%); Vila Esperança (22,6\%); Jardim São Paulo (18,9\%); Taquara (18,4\%); Vila Barreiros $(17,1 \%)$; São Benedito (14,7\%) e por último o Bairro Frei Júlio $(9,7 \%)$.

Observando a Tabela 8, no tocante à acessibilidade, corrobora a necessidade de assistência técnica nas edificações e planejamento habitacional, o fato que o conjunto habitacional Paulo Freire, detém 100\% de moradias com acessibilidade, ao contrário dos planejamentos insuficientes nos Bairros com famílias enquadradas na menor faixa de renda (Tabela 3 ) que detém elevados índices de ausência de domicílios com a acessibilidade aos portadores de deficiência, como as moradias dos Bairros Solidariedade (100\%); Vila Progresso (100\%); Vila Esperança (83,9\%); Cidade Nova (80\%) e assim sucessivamente.

A Tabela 9 mostra o perfil das moradias levando em consideração os bairros e os percentuais relativos ao número de dormitórios e número de pessoas por dormitório.

Tabela 9 - Perfil das moradias em relação aos Bairros versus número de dormitórios e número de pessoas por dormitório.

\begin{tabular}{l|r|r|r|r|r|r|r|r|r}
\hline \multirow{2}{*}{ Bairros } & \multicolumn{3}{|c|}{ Número de Dormitórios } & \multicolumn{4}{c}{ Número de pessoas por dormitório } \\
\cline { 2 - 9 } & De 1 a 2 & De 3 a 4 & De 5 a 6 & Total & De 1 a 2 & De 3 a 4 & De 5 a 6 & De 7 a 8 & Total \\
\hline Cidade Nova & $85,7 \%$ & $5,7 \%$ & $8,6 \%$ & $100,0 \%$ & $62,9 \%$ & $25,7 \%$ & $5,7 \%$ & $5,7 \%$ & $100,0 \%$ \\
Conjunto Paulo Freire & $100,0 \%$ & - & - & $100,0 \%$ & $100,0 \%$ & - & - & - & $100,0 \%$ \\
Frei Júlio & $87,1 \%$ & $6,5 \%$ & $6,5 \%$ & $100,0 \%$ & $25,8 \%$ & $64,5 \%$ & $9,7 \%$ & - & $100,0 \%$ \\
Jardim São Paulo & $78,4 \%$ & $13,5 \%$ & $8,1 \%$ & $100,0 \%$ & $51,4 \%$ & $43,2 \%$ & $2,7 \%$ & $2,7 \%$ & $100,0 \%$ \\
São Benedito & $79,4 \%$ & $17,6 \%$ & $2,9 \%$ & $100,0 \%$ & $52,9 \%$ & $41,2 \%$ & $5,9 \%$ & - & $100,0 \%$ \\
Solidariedade & $100,0 \%$ & - & - & $100,0 \%$ & $100,0 \%$ & - & - & - & $100,0 \%$ \\
Tancredo Neves & $100,0 \%$ & - & - & $100,0 \%$ & $50,0 \%$ & $50,0 \%$ & & & $100,0 \%$ \\
Taquara & $59,2 \%$ & $28,6 \%$ & $12,2 \%$ & $100,0 \%$ & $44,9 \%$ & $44,9 \%$ & $6,1 \%$ & $4,1 \%$ & $100,0 \%$ \\
Vila Barreiros & $71,4 \%$ & $22,9 \%$ & $5,7 \%$ & $100,0 \%$ & $48,6 \%$ & $40,0 \%$ & $8,6 \%$ & $2,9 \%$ & $100,0 \%$ \\
Vila Esperança & $93,5 \%$ & $6,5 \%$ & - & $100,0 \%$ & $64,5 \%$ & $29,0 \%$ & $6,5 \%$ & - & $100,0 \%$ \\
Vila Jacaréy & $60,0 \%$ & $20,0 \%$ & $20,0 \%$ & $100,0 \%$ & $50,0 \%$ & $50,0 \%$ & - & - & $100,0 \%$ \\
Vila Progresso & $100,0 \%$ & - & - & $100,0 \%$ & $100,0 \%$ & - & - & - & $100,0 \%$ \\
Vilinha & $100,0 \%$ & - & - & $100,0 \%$ & $50,0 \%$ & $50,0 \%$ & - & - & $100,0 \%$ \\
\hline
\end{tabular}

Fonte: Pesquisa no banco de dados do CRAS-Sul (2017) 
- Perfil das moradias em relação aos Bairros versus número de dormitórios e número de pessoas por dormitório: a predominância da variável número de dormitórios, concentra-se de 1 a 2 dormitórios. Esta concentração enfatiza-se nos bairros mais carentes como Vila Progresso (100\%); Vilinha (100\%); Tancredo Neves (100\%); Solidariedade (100\%) e excepcionalmente o Bairro Paulo Freire, que por ser um conjunto habitacional popular, por padrão tem 2 quartos.

Novamente pelos dados analisados, indica como prioridade de ação da legislação nos Bairros mais carentes, que mantém de 5 a 8 pessoas por dormitório, que em ordem decrescente dispõe: Cidade Nova (11,4\%), Taquara (10,5\%); Vila Barreiros (11,5\%); Frei Júlio (9,7\%); Vila Esperança (6,5\%); São Benedito (5,9\%) e Jardim São Paulo (5,4\%).

\section{Considerações Finais}

Esse trabalho teve como objetivo analisar a aplicação da Lei Federal n ${ }^{\circ}$ 11.888/08, que trata da assistência técnica pública e gratuita para o projeto e a construção de habitação de interesse social, com relação aos potenciais benefícios para as famílias que recebem até três salários mínimos. Assim foi realizado um diagnóstico da situação habitacional das moradias de famílias com renda inferior a três salários mínimos, assistidas pelo Centro de Referência de Assistência Social - CRAS-Sul (PMTO, 2017) que é composto pelos bairros Cidade Nova, Frei Júlio, Jardim São Paulo, São Benedito, Taquara, Vila Barreiros, Vila Esperança (que engloba Vilinha), Vila Jacaré e Vila Progresso (que engloba Tancredo Neves) do Município de Teófilo Otoni, esse diagnóstico considerou o período de 2012 a 2017. Sendo importante para identificar a necessidade da aplicação dos benefícios da Lei Federal no $11.888 / 08$, nas principais demandas e prioridades habitacionais nos bairros carentes estudados.

A partir da análise dos questionários respondidos pelos moradores da região sul de Teófilo Otoni-MG aos técnicos responsáveis do CRAS-Sul, foi possível definir alguns fatores causa e/ou consequência e frequências com que estas carências atingem cada bairro desta região. O resultado levou a estabelecer prioridades de ação corretiva e preventiva por bairro no contexto das benesses legais.

A partir do trabalho, pôde-se perceber que algumas das principais causas das edificações irregulares, ausência sanitária e outras deficiências das moradias das famílias com renda total de até três salários mínimos da Zona sul do município de Teófilo Otoni, estão na ausência de assistência técnica pública gratuita como política habitacional, induzindo estas a moradia à margem da dignidade humana.

Concluiu-se que os bairros com maiores prioridades são: Jardim São Paulo, Taquara, Cidade Nova, Vila Barreiros e Vila Esperança, uma vez que apresentam os piores índices no tocante às variáveis analisadas: área de risco, rede de esgoto, coleta de lixo, difícil acesso geográfico, domicílio em área de violência, tipo de residência, medidor de energia individual, número total de cômodos, domicílio com acessibilidade de locomoção, número de dormitórios, número de pessoa por dormitório.

No intuito de contribuir para possíveis respostas para a questão principal desta pesquisa - Quais fatores são responsáveis pela ausência de acompanhamento técnico e gratuito para o projeto e a construção de habitação de interesse social, para as famílias que recebem até três salários mínimos nos bairros carentes da região sul de Teófilo Otoni? - foram esboçados alguns comentários, principalmente sobre os fatores que induzem a carência das moradias das famílias:

Especialização dos Atores Envolvidos, como já apontado, dentre os entraves para a aplicação da Lei 11.888/08, está a falta do conhecimento técnico para gerir e executar(?) o que é disposto. Como exemplo dos desafios, é necessário que engenheiros e arquitetos tenham incentivo dos transformadores do conhecimento, isto é, das instituições de ensino, particularmente das públicas, de modo a adquirir conhecimento aprofundado sobre urbanismo, sustentabilidade, conforto térmico, acústico, eficiência energética, tecnologias alternativas de custo reduzido, gerenciamento, relações públicas, planejamento, estratégia, metodologia, parâmetros aplicáveis, diretriz, dentre outros, que venham a permitir resultados 
eficientes com maior rentabilidade, redução de custos e sustentáveis.

Comprometimento em busca desta eficiência: faz-se necessário que sejam preparados profissionais que além de serem remunerados, estejam imbuídos em uma nova filosofia, voltados a e comprometidos com obras de interesse social, bem como em ações voltadas a promover qualidade, elevação de autoestima da população mais carente, inclusão social e acessibilidade;

Divulgação de experiências dos erros e acertos nas redes sociais, fóruns, debates, congressos e demais meios. Definidos os parâmetros e modelos de gestão, que sejam confeccionadas cartilhas, manuais e ferramentas a serem distribuídas entre os atores envolvidos, na busca de um piso de conhecimento e enriquecimento de capacitação técnica;

Sociabilidade, por serem parcos os recursos dos atendidos pela legislação supra, além da necessidade do técnico especializado, há a carência dos recursos financeiros para custear a mão-de-obra do executor. Desta forma, com o incentivo e administração dos entes, associações, líderes, movimentos, etc., podem ser planejados mutirões sociais autogeridos, em que os próprios moradores, sob a orientação e supervisão técnica, realizam as obras necessárias às residências dos acobertados por esta lei;

O cooperativismo, além da interação social dos moradores locais, promove outras benesses, como a aceleração das obras, redução de conflitos internos, redução da inadimplência dos financiamentos realizados nos órgãos e instituições financeiras para custear a mão-de-obra e aumento da possibilidade de aquisição do material para a construção;

O uso de tecnologia específica revolucionária a sistemática adotada. Porém, tal acesso só se faz possível com a presença do técnico e com sua devida capacitação e especialização. Existem softwares com capacidade de desenhar as instalações das residências em três dimensões, permitindo ao usuário a prever de forma detalhada sua obra concluída. Pelo planejamento, se faz possível a promoção de toda e qualquer adequação, redução de custos e performance. A partir do uso da ferramenta, é possível a aplicação prática dos conceitos: a. Usabilidade - esforço físico e cognitivo, grau de satisfação após a execução. b. Aplicabilidade - ser personalíssimo. c. Criativo - conduzir ao residente a interagir entre o pretendido e ideal;

Projeto de Convênio das instituições de Ensino e Poder Executivo Municipal. Dentre as propostas, está a possibilidade, por iniciativa do Poder Legislativo Municipal, em editar um Projeto de Lei que venha propor um convênio entre o Poder Executivo Municipal com as Empresas Júnior ligadas às instituições de ensino, técnicos da área de Engenharia e Arquitetura, objetivando a aplicação dos recursos financeiros Federais destinados a melhoria habitacional da população de baixa renda, nos termos da Lei 11.888/08.

Delimitando-se a análise dos benefícios ofertados pela Lei Federal de $n^{\circ} 11.888 / 08$, percebeu-se que a ausência de informação tanto por parte da população carente quanto dos técnicos, bem como, o desinteresse dos governantes, impede que a família com renda não superior à três salários mínimos tenha acesso à assistência técnica pública gratuita.

\section{Sugestões para trabalhos futuros}

A partir do estudo abordado e dos questionários respondidos pela população atendida pelos CRAS de Teófilo OtoniMG, sugere-se os seguintes trabalhos futuros: a) análise por região. Esta modalidade permitirá que se tenha um levantamento detalhado das prioridades de ação para reduzir o déficit habitacional, por região e no município como um todo; b) trabalho de divulgação. A divulgação para a camada fim, permitirá a redução do distanciamento entre os benefícios disponíveis pelo governo Federal nos termos da Lei 11.888/08 e a população a ser atingida; c) trabalho de especialização dos técnicos da área. A especialização permitirá melhor qualidade dos trabalhos a serem realizados nos pontos abordados pelas análises; d) confecção de Projeto pela Câmara Municipal para autorizar convênio entre o Poder Executivo, técnicos e instituições de ensino superior, para conceder os benefícios propostos pela Lei Federal de $\mathrm{n}^{\circ}$ 11.888/08; e) desenvolvimento de pesquisa sobre a disponibilização de software para apresentação virtual e antecipada da obra futura.

Por fim, pretende-se que essa pesquisa possa proporcionar elementos para ações nos moldes dos benefícios ofertados 
pela Lei Federal 11.888/08, de modo que, a curto e longo prazo, haja melhor qualidade de vida, autoestima, redução de riscos, profilaxia, preservação à saúde e à vida, valorização aos deficientes físicos, principalmente à população que pertence à faixa mais carente que se trata das famílias que detém renda familiar em até três salários mínimos, além de melhoria visual das regiões periféricas do município de Teófilo Otoni-MG.

\section{Referências}

Bonduki, N. (2002). Origens da habitação social no Brasil: a produção rentista de habitação e o autoritarismo da ordem sanitária. São Paulo: Editora Estação Liberdade.

Brasil. (1998). Constituição da República Federativa do Brasil. Brasília, DF: Senado Federal: centro gráfico. Diário oficial [da] República Federativa do Brasil, Brasília, DF. Acessado em http://www.planalto.gov.br/ccivil_03/constituicao/constituicaocompilado.htm.

Brasil. (2005). Lei $\mathrm{N}^{\circ} 11.888$ de 24 de dezembro de 2008. Assegura às famílias de baixa renda assistência técnica pública e gratuita para o projeto e a construção de habitação de interesse social e altera a Lei n 11.124. Diário Oficial [da] República Federativa do Brasil, Brasília, DF. Acessado em http://www6.senado.gov.br/legislacao/ListaPublicacoes.action?id=258240.

Fernandes, E., \& Alfonsin, B. (2014). Direito à moradia adequada: o que é para quem serve, como defender e efetivar. Fórum.

Freitas, E. L. H. F. (2004). Como qualificar conjuntos habitacionais populares. Brasília: Caixa Econômica Federal. Brasília: Caixa Econômica Federal. 200p.

G1 Vales MG - MG Inter TV 2a Edição. (2013). Problemas na infraestrutura do bairro Cidade Nova preocupam moradores. http://g1.globo.com/mg/vales$\mathrm{mg} / \mathrm{mgintertv}$-2edicao/videos/v/moradores-do-bairro-cidade-nova-em-teofilo-otoni-estao-amendrontados-com-barranco/2889716/.

G1 Vales MG - MG Inter TV 2a Edição. (2017). As casas da rua Altamiro Nunes Leite, na Vila Jacaré, ficam abaixo do nível da via. http://g1.globo.com/mg/vales-mg/videos/v/moradores-em-teofilo-otoni-vivem-com-medo-de-veiculos-cairem-no-telhados-das-casas/2748425/.

Gil, A. C. (2008). Como elaborar projetos de pesquisa. Atlas.

Mastrodi, J., \& Martins, E. G. (2018). Direito à moradia: entre a efetivação autônoma e a sujeição ao direito de propriedade. Revista direitos fundamentais e democracia, 23(2), 75-103, 10.25192/issn.1982-0496.rdfd.v23i2760.

Mitidiero, D. (2007). Processo civil e Estado constitucional. Livraria do Advogado.

Moraes, A. P. de. (2012). Limites e potencialidades da assistência técnica pública e gratuita para projeto, construção e melhoria da habitação popular na cidade de Viçosa, MG. Dissertação (Mestrado em Engenharia Civil) - Universidade Federal de Viçosa.

Moraes, J. (2017). Assistência técnica para projeto é garantia ao direito à cidade. Instituto de Arquitetos do Brasil. Acessado em https://www.caurj.gov.br/assistencia-tecnica-para-projeto-e-garantia-ao-direito-a-cidade/.

Pmto Prefeitura Municipal de Teófilo Otoni. (2015). Secretaria Municipal de Educação - Plano Municipal de Educação 2015 - 2024. Acessado em http://www.teofilootoni.mg.gov.br/site/wp-content/uploads/2015/06/Plano-Municipal-2015-2024-corrigido-reda\%C3\%A7\%C3\%A3o-final.pdf.

Prado, V. J. do, \& Santos, J. A. G. dos. (2020). A cidade como o espaço do habitar e a ideia da fábrica de cidades. Research, Society and Development, 9(2), e197922237. Doi: http://dx.doi.org/10.33448/rsd-v9i2.2237

Previdência Social. (2017). CRAS SUL de Teófilo Otoni, MG. IBGE: 316860. http://previdencia.social/cras/teofilo-otoni-mg/.

Rádio Teófilo Otoni. (2016). Prefeitura de Teófilo Otoni prepara entrega das moradias do Conjunto Paulo Freire. http://www.radioteofilotoni.com.br/noticia/prefeitura-de-teofilo-otoni-prepara-entrega-das-moradias-populares-do-conjunto-paulo-freire-5289.

Reis, A. T. L., \& Lay, M. C. D. (2010). O projeto da habitação de interesse social e a sustentabilidade social. Ambiente Construído. 10(3), 99-119. https://doi.org/10.1590/S1678-86212010000300007

Rolnik, R., Cymbalista, R., \& Nakano, K. (2008). Solo Urbano e Habitação de Interesse Social: a questão fundiária na política habitacional e urbana do país. Revista de Direito da ADVOCEF, VII(13), 123-158. http://raquelrolnik.files.wordpress.com/2013/04/solo-urbano-e-his-rolnik-nakano-cymbalista.pdf.

Santos JR., O. A., \& Montandon D. T. (2012). Os planos diretores municipais pós - Estatuto da Cidade: balanço crítico e perspectivas. Rio de Janeiro: Observatório das Metrópoles/Letra Capital.

Santos, C. S. (2006). A política habitacional para a população de baixa renda, em Belo Horizonte, a partir de 1990. Tese (Doutorado Arquitetura e Urbanismo) - Programa de Pós-Graduação Arquitetura e Urbanismo, Universidade Federal de São Paulo, São Paulo.

Santos, J. S. (2016). Lei da assistência técnica pública e gratuita: um estudo de aplicação para municípios paraibanos. 118 f. Dissertação (Mestrado em Arquitetura e Urbanismo) - Universidade Federal da Paraíba, João Pessoa.

Schramm, F.R., \& Castiel, L.D. (1992). Processo saúde/doença e complexidade em epidemiologia. Cadernos de Saúde Pública. Rio de Janeiro: Fiocruz, 8(4), 379-390. http://dx.doi.org/10.1590/S0102-311X1992000400004.

Silvestre, A. L. (2007). Análise de Dados e Estatística Descritiva. Forte da Casa: Escolar Editora. 
Research, Society and Development, v. 10, n. 4, e4210413866, 2021

(CC BY 4.0) | ISSN 2525-3409 | DOI: http://dx.doi.org/10.33448/rsd-v10i4.13866

Vieira, A. A., \& Bastos, T. P. (2020). Habitações para famílias de baixa renda: estratégias de implantação de assistência pública gratuita. Research, Society and Development, 9(7), e167973770. http://dx.doi.org/10.33448/rsd-v9i7.3770

Watt, P. (2018). Gendering the right to housing in the city: Homeless female lone parents in post-Olympics, austerity East London. Cities, 76, 43-51. http://dx.doi.org/10.1016/j.cities.2017.04.005 